\title{
Volunteer Fire Fighter Dies After Running Out of Air and Becoming Disoriented in Retail Store in Strip Mall Fire-North Carolina
}

\section{Executive Summary}

On April 30, 2016, a 20-year-old male volunteer fire fighter died after he ran out of air and became disoriented while fighting a fire in a commercial strip mall. The fire fighter was a member of the first-due engine company, Engine 3 from Department 7. Once Engine 3 arrived onscene, a preconnected 13/4-inch crosslay was stretched into the 7,000-square-foot retail store to attack the fire. The Engine 3 hoseline crew consisted of a senior captain, a lieutenant, and two fire fighters. After the fire was located and water was flowed on the fire, a fire fighter working the nozzle ran low on air, gave the nozzle to the second fire fighter (victim), and proceeded to follow the hoseline to exit the structure. While operating the nozzle near the Charlie/Delta corner of the retail store,

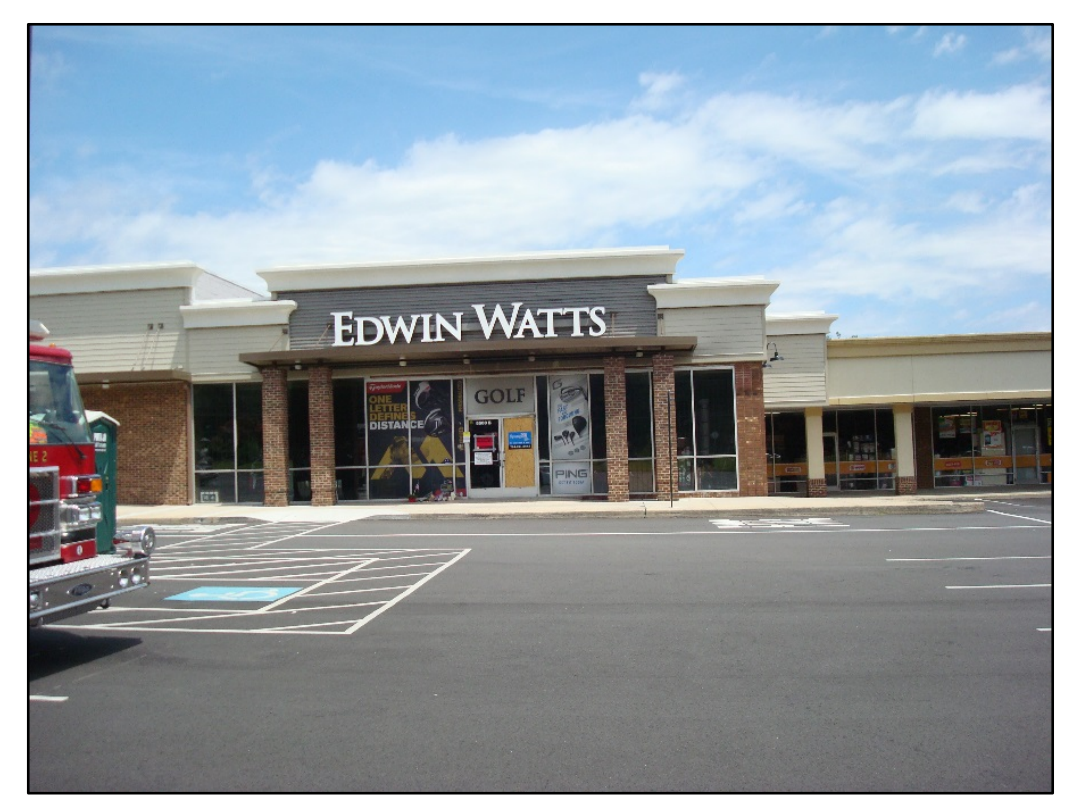

Retail golf store in middle of commercial strip mall where 20-year-old fire fighter was fatally injured. (Photo NIOSH.) the remaining fire fighter also ran low on air and told the lieutenant and captain that he had to go outside. He immediately tried to exit but quickly became disoriented in the near-zero visibility conditions within the retail store. The fire fighter returned to the hoseline near the nozzle and the lieutenant and captain tried to calm him down. The lieutenant was low on air and told the captain that he would take the fire fighter outside but the fire fighter broke away and disappeared into the thick smoke toward Side C, the rear of the store. The lieutenant began to follow the hoseline out. He heard the missing fire fighter yelling for help off to his right and tried to make his way toward the missing fire fighter but became entangled in the display racks. After freeing himself, the lieutenant briefly located the missing fire fighter who stated he was completely out of air and had to get out. The fire fighter again disappeared, moving toward the rear of the store. The lieutenant also ran out of air and had to remove his helmet and facepiece because his facepiece was fogging up. The lieutenant activated his PASS device and was soon located by the Engine $16 \mathrm{crew}$ and helped outside. The lieutenant told rescuers that the fire fighter was missing inside the store. A Mayday was transmitted by the Engine 20 captain at the front door for a missing fire fighter. The Engine 3 fire fighter was located about 2 
Volunteer Fire Fighter Dies After Running Out of Air and Becoming Disoriented in Retail Store in Strip Mall Fire-North Carolina

minutes later and transported to the hospital where he was pronounced dead. The lieutenant was transported to the hospital for treatment of smoke inhalation and was released later that day.

\section{Contributing Factors}

- Lack of crew integrity

- Inadequate air management training

- Inexperienced fire fighter

- Ineffective fireground communications

- Failure to call a Mayday in a timely manner

- No sprinkler system in commercial structure

- Zero-visibility conditions in smoke-filled retail store

- Restricted mobility due to arrangement of floor displays.

\section{Key Recommendations}

- Fire departments should ensure that crew integrity is properly maintained by sight, voice, or radio contact when operating in an immediately-dangerous-to-life-or-health (IDLH) atmosphere.

- Fire departments should ensure all fire fighters are trained on and actively practice air management principles.

- State, local and municipal governments, building owners, and authorities having jurisdiction should consider requiring the use of sprinkler systems in commercial structures.

- Fire departments should train company officers and fire fighters to report interior conditions to the incident commander as soon as possible and on a regular basis.

- Dispatch centers should provide timeframe bench marks to Incident Command on a regular basis.

- Fire departments should ensure that fire fighters are trained and proficient on following hoselines outside as a means for egress and self-rescue.

The National Institute for Occupational Safety and Health (NIOSH), an institute within the Centers for Disease Control and Prevention (CDC), is the federal agency responsible for conducting research and making recommendations for the prevention of work-related injury and illness. In 1998, Congress appropriated funds to NIOSH to conduct a fire fighter initiative that resulted in the NIOSH Fire Fighter Fatality Investigation and Prevention Program, which examines line-of-duty deaths or on-duty deaths of fire fighters to assist fire departments, fire fighters, the fire service, and others to prevent similar fire fighter deaths in the future. The agency does not enforce compliance with state or federal occupational safety and health standards and does not determine fault or assign blame. Participation of fire departments and individuals in NIOSH investigations is voluntary. Under its program, NIOSH investigators interview persons with knowledge of the incident who agree to be interviewed and review available records to develop a description of the conditions and circumstances leading to the death(s). Interviewees are not asked to sign sworn statements and interviews are not recorded. The agency's reports do not name the victim, the fire department, or those interviewed. The NIOSH report's summary of the conditions and circumstances surrounding the fatality is intended to provide context to the agency's recommendations and is not intended to be definitive for purposes of determining any claim or benefit.

For further information, visit the program website at www.cdc.gov/niosh/fire or call toll free 1-800-CDC-INFO (1-800-232-4636). 


\section{Volunteer Fire Fighter Dies After Running Out of Air and Becoming Disoriented in Retail Store in Strip Mall Fire-North Carolina}

\section{Introduction}

On April 30, 2016, a 20-year-old male volunteer fire fighter died after he ran out of air and became disoriented while fighting a fire in a commercial strip mall. The fire fighter was a member of the initial engine company who advanced a preconnected 13/4-inch crosslay into the retail store to attack the seat of the fire. On May 2, 2016, the U.S. Fire Administration notified the National Institute for Occupational Safety and Health (NIOSH) of this incident. On May 15, 2016, a safety engineer, a general engineer, and an investigator with the NIOSH Fire Fighter Fatality Investigation and Prevention Program traveled to North Carolina. The NIOSH investigators met with representatives of the fire department and the assistant fire marshal from the county where the incident occurred. The NIOSH investigators visited the incident site and took photographs and measurements. The NIOSH investigators interviewed members of the volunteer fire department who were involved in the incident. The NIOSH investigators also interviewed members of both the career department and the volunteer department who responded to the incident for mutual aid. The NIOSH investigators also met with representatives of the North Carolina Department of Labor, the city police department, the county medical examiner's office who performed the autopsy, the county emergency medical services (EMS) agency, and county fire dispatch center. The NIOSH investigators obtained copies of the fire fighter's training records, fire department standard operating procedures, building information, and the dispatch audio records for the incident.

On June 20, 2016, NIOSH investigators returned to North Carolina and met with representatives of the fire department and the city police department. The NIOSH investigators took possession of two selfcontained breathing apparatus (SCBA) that were used by the two fire fighters who ran out of air inside the structure. These SCBA were transported to the SCBA manufacturer's facility where the SCBA data logger information was downloaded. This process was witnessed by representatives of the fire department, the county fire marshal's office, the North Carolina Department of Labor, and NIOSH. Following this process, the SCBA were transported to the NIOSH National Personal Protective Technology Laboratory (NPPTL) in Morgantown, West Virginia, for secure storage. See Appendix One for further information on the NPPTL SCBA Evaluation Report.

On August 15, 2016, the two SCBA were tested by the NIOSH NPPTL staff. The testing was witnessed by representatives of the fire department, the county fire marshal's office, the North Carolina Department of Labor, and the NIOSH Fire Fighter Fatality Investigation and Prevention Program. 


\section{Volunteer Fire Fighter Dies After Running Out of Air and Becoming Disoriented in Retail Store in Strip Mall Fire-North Carolina}

\section{Fire Department}

This combination fire department was an incorporated entity that provided fire suppression and other emergency services under contract within the city limits where this incident occurred. At the time of the incident, the fire department had 50 members including 28 trained interior fire fighters who operated out of one station that served a population of approximately 7,900 within an area of about 3.5 square miles.

The fire department had four paid fire fighters who were trained fire fighter/emergency medical technicians (EMTs). These fire fighters provided coverage 5 days per week during 0700 hours through 1800 hours. One paid fire fighter worked from 0700 hours to 1600 hours. Two fire fighters worked from 0800 hours to 1700 hours, and one fire fighter worked from 0900 hours to 1800 hours. There was no paid coverage from 1800 hours to 2100 hours. Fire fighters could work overtime shifts from 2100 hours to 0600 hours.

The fire department had a fire chief, three assistant chiefs, one senior captain, four captains, and five lieutenants. One lieutenant served as the department safety officer. The fire chief and assistant chiefs were voted in by the membership. All lieutenants and captains were appointed by the fire chief. All fire department members received an annual physical examination that complied with NFPA 1582 Standard on Comprehensive Occupational Medical Program for Fire Departments. All interior fire fighters were respirator fit-tested on an annual basis.

The fire department operated three engines, one tower ladder truck (105-foot ladder), one brush truck, one heavy rescue, and one light duty rescue (squad) vehicle. The fire department rotated the engines on a regular basis to limit the hours of operation on each engine. Engine 2 was operated on evennumbered days. Engine 3 was operated on odd-numbered days, and Engine 4 was operated every Wednesday. The fire department responded to approximately 2600 emergency calls in 2015 and at the time of this investigation was on a pace to respond to approximately 3000 emergency calls in 2016. The fire department had automatic aid agreements with neighboring volunteer departments within the county and also had a mutual aid agreement with the nearby metro-sized career fire department.

The fire department was classified by Insurance Services Office (ISO) as a Class 5 fire department. In the ISO rating system, Class 1 represents exemplary fire protection, and Class 10 indicates that the area's fire-suppression program does not meet ISO's minimum criteria.

\section{Training and Experience}

The state of North Carolina does not have minimum training requirements for a fire fighter to be an interior fire fighter. In the state of North Carolina, fire fighters are required to receive 36 hours of training each year, and each fire chief is responsible for setting departmental training requirements. The fire department involved in this incident strives to have all interior fire fighters trained to both Fire Fighter I and Fire Fighter II equivalent to the National Fire Protection Association (NFPA) 1001 


\section{Volunteer Fire Fighter Dies After Running Out of Air and Becoming Disoriented in Retail Store in Strip Mall Fire-North Carolina}

Standard for Fire Fighter Professional Qualifications and 1403 Standard on Live Fire Training Evolutions [NFPA 2012, 2013a].

The fire department did not have an officer development training program for a member to become an officer. At the time of this incident, the fire department required a fire fighter to be an active member for 3 years as an active interior fire fighter before being able to serve as an officer. All lieutenants and captains were appointed by the fire chief.

The Engine 3 fire fighter who was critically injured and died following this incident had been a volunteer member of the fire department for less than 3 years. Fire department records indicated the fire fighter had received 127 documented hours of training during 2014, 198 documented hours of training during 2015, and 23.5 documented hours of training during 2016 at the fire department. Subjects included appartus familiarization, truck tools, building construction, SCBA use, personal protective equipment (PPE), Fire Fighter I, and Fire Fighter II. Records from the North Carolina Department of Insurance, Fire \& Rescue Commission identified International Fire Service Accreditation Congress (IFSAC) certification in a number of subjects including:

- Emergency Vehicle Driver/Operator

- Hazardous Materials Level 1

- Firefighter Level I

- Firefighter Level II

The Engine 3 lieutenant had been a member of the fire department for 5 years and was working an overtime shift (2100 hours - 0600 hours) at the time of this incident. He also worked as a career fire fighter at the nearby metro-sized fire department. Fire department records indicated the lieutenant had received 87.5 documented hours of training during 2014, 52 documented hours of training during 2015, and 10 documented hours of training during 2016 at the fire department. The lieutenant also received significant training at the career fire department.

The Engine 3 senior captain had 29 years of experience at the combination fire department. Fire department records indicated the senior captain had received 64.5 documented hours of training during 2014, 68.5 documented hours of training during 2015, and 8 documented hours of training during 2016 at the fire department. The senior captain had received certification through the North Carolina Department of Insurance, Fire \& Rescue Commission in Firefighter Level I, Firefighter Level II, Hazardous Materials Responder with PPE Certification, Basic Rescue Technician, Emergency Rescue Technician, and several others.

The fire chief of Department 7 (who was the incident commander) had 27 years experience at the combination fire department and had been the fire chief for 2 years at the time of the incident. Fire department records indicated the fire chief had received 63.5 documented hours of training during 2014, 110.5 documented hours of training during 2015, and 14 documented hours of training during 2016 at the fire department. The fire chief of Department 7 was also a captain at the nearby metrosized career fire department with 15 years total experience working for the career fire department. The 


\section{Volunteer Fire Fighter Dies After Running Out of Air and Becoming Disoriented in Retail Store in Strip Mall Fire-North Carolina}

fire chief had received certifications on a number of subjects both through the North Carolina Department of Insurance, Fire \& Rescue Commission and the International Fire Service Accreditation Congress (IFSAC). The fire chief also received significant training at the career fire department.

\section{Equipment and Personnel}

This incident involved the local combination fire department (Department 7) being dispatched for the report of smoke in a commercial strip mall. Department 2 was dispatched for automatic mutual aid. The following units from Department 7 responded on the initial dispatch on April 30, 2016:

- Engine 3 from Department 7: senior captain, driver (captain), two lieutenants, and two fire fighters including the victim (Fire Fighter 2).

- Ladder 1 from Department 7: assistant chief and one fire fighter

- Squad 8 from Department 7: two fire fighters and two junior fire fighters

- Car 7 from Department 7: fire chief

- Five Department 7 fire fighters responded to the scene via privately-owned vehicle (POV).

The neighboring volunteer Department 2 was dispatched on automatic mutual aid. Their initial response consisted on the following unit:

- Engine 3 from Department 2: captain and fire fighter. The fire fighter made entry with the Department 7 second hoseline.

The Department 7 fire chief arrived on-scene and assumed incident command. A ladder company from the nearby city fire department was in the area on a medical call. The incident commander radioed dispatch and requested that the ladder company be added to the assignment. The following career fire department company was added:

- Ladder 24: captain, driver, two fire fighters.

After confirming that a working fire was in progress, the Department 7 fire chief (incident commander) radioed Dispatch and requested a first alarm assignment from the city fire department. The following units and fire fighters were dispatched:

- Engine 39: captain, driver and two fire fighters

- Engine 26: captain, driver and two fire fighters

- Engine 20: captain, driver and one fire fighter

- Engine 16: relief captain, driver and two fire fighters

- $\quad$ Rescue 10

- Battalion Chief 5 


\section{Volunteer Fire Fighter Dies After Running Out of Air and Becoming Disoriented in Retail Store in Strip Mall Fire-North Carolina}

\section{Structure}

The building was part of a 70,000-square-foot commercial strip mall complex. The strip mall complex was originally built in 1978 (see Photo 1).

The fire occurred in a 7,037-square-foot retail store that measured 50 feet wide and 140 feet 9 inches deep and housed a retail golf store. The front (Side Alpha) was constructed entirely of plate-glass windows with a center entrance doorway protected by a metal security gate (see Photo 2). Side Bravo and Side Delta were constructed of concrete block fire walls approximately 12 feet high. A storage room, offices, and rest rooms were located at the rear of the structure. A closed fire door was located at the rear (Side Charlie) near the Charlie/Delta corner and was used for employee entrance only. The front door at Side Alpha provided the only means of normal ingress and egress to the store. The flat roof consisted of a metal roof deck covered by three layers of asphalt, foam, and waterproof membrane covered by asphalt and gravel (see Photo 3 and Photo 4). The one-story building rested on a concrete pad. The building did not contain a sprinkler system or automatic fire suppression system.

The store was serviced by both natural gas and electrical utilities. The electrical panel was located at the Charlie/Delta corner of the store near the origin of the fire.

The county fire marshal's office investigators determined that the fire was likely caused by a lightning strike that hit the roof near the rear of the building [Weather Underground 2016]. Weather records and police department interviews with witnesses in the area indicated that heavy thunderstorms, rain, lightning, and loud thunder were observed in the immediate area around 2000 hours through 2100 hours. 


\section{Volunteer Fire Fighter Dies After Running Out of Air and Becoming Disoriented in Retail Store in Strip Mall Fire-North Carolina}

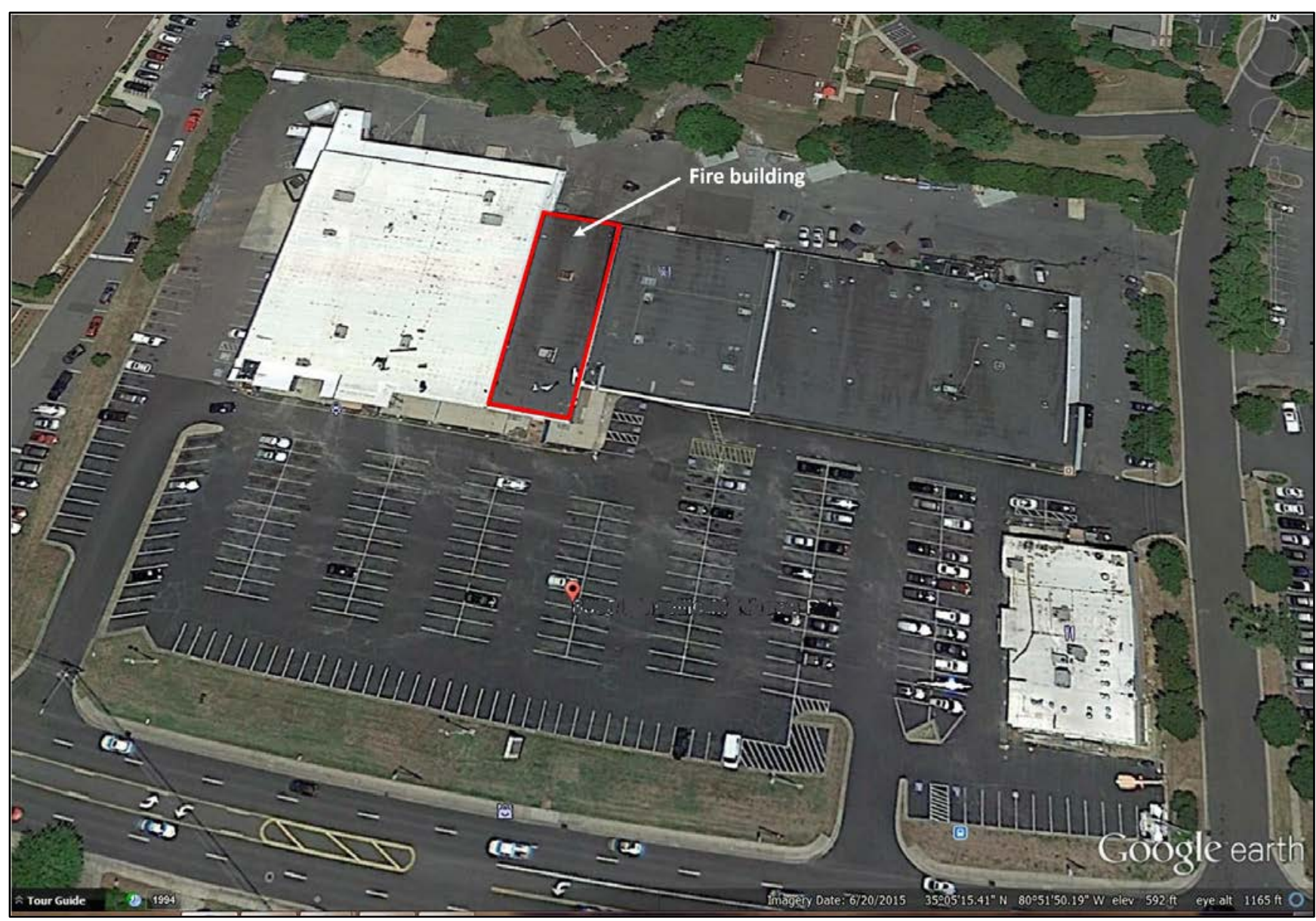

Photo 1. Overhead view of commercial strip mall where incident occurred. The fire building was a retail golf store where the $\mathbf{2 0}$-year-old fire fighter was fatally injured (fire building is highlighted in red).

(Photo adapted from Google Earth.) 


\section{Volunteer Fire Fighter Dies After Running Out of Air and Becoming} Disoriented in Retail Store in Strip Mall Fire-North Carolina

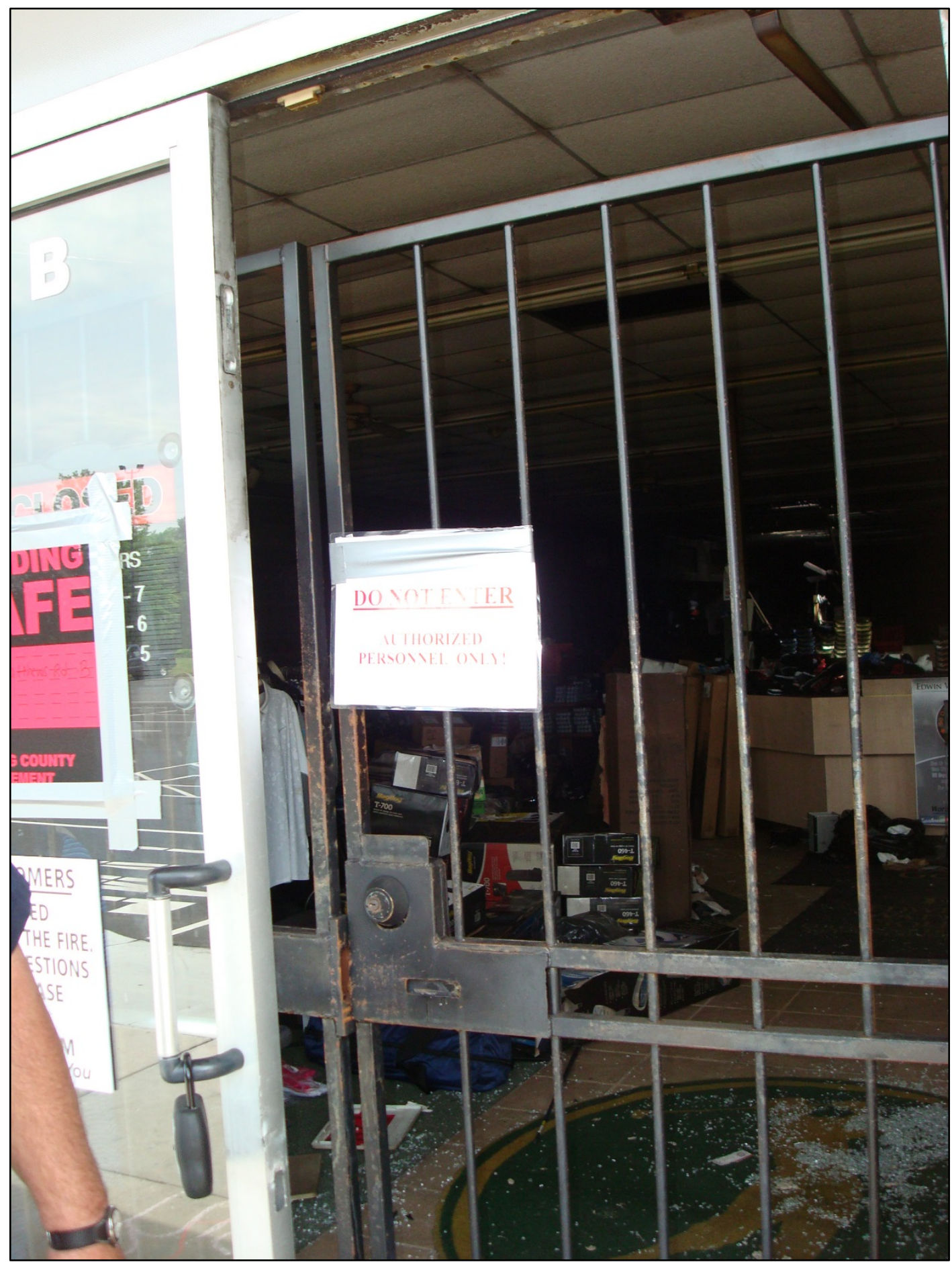

Photo 2. Photo shows sliding plate-glass entrance door and metal security gate. (NIOSH photo.) 


\section{Volunteer Fire Fighter Dies After Running Out of Air and Becoming Disoriented in Retail Store in Strip Mall Fire-North Carolina}

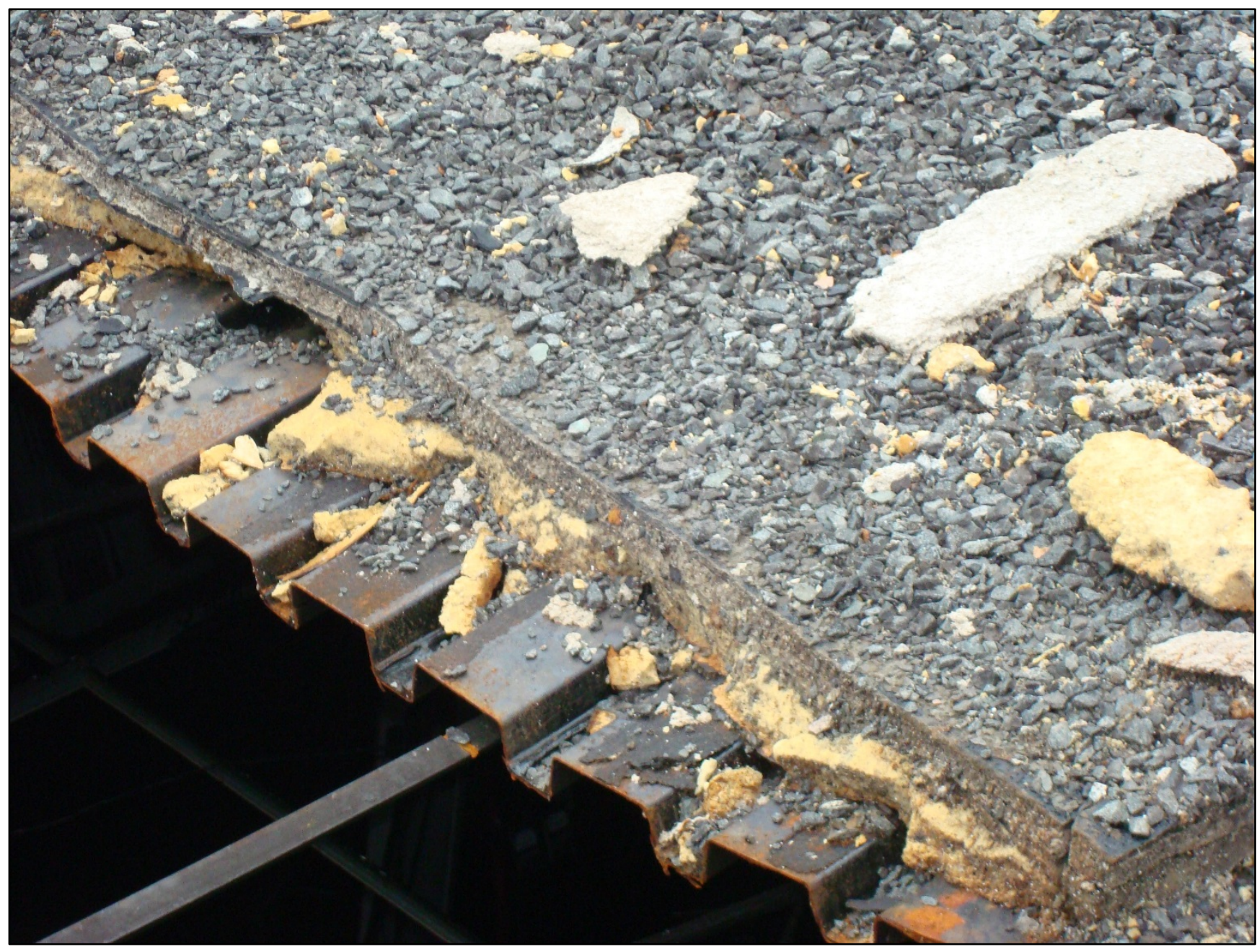

Photo 3. Photo shows construction of flat metal roof covered with asphalt, foam insulation, and gravel. Chain saws were initially used in an effort to open the roof for vertical ventilation but would not cut through the metal deck. K12 saws with metal cutting blades had to be retrieved to cut through the roof deck.

(NIOSH photo.) 


\section{Volunteer Fire Fighter Dies After Running Out of Air and Becoming Disoriented in Retail Store in Strip Mall Fire-North Carolina}

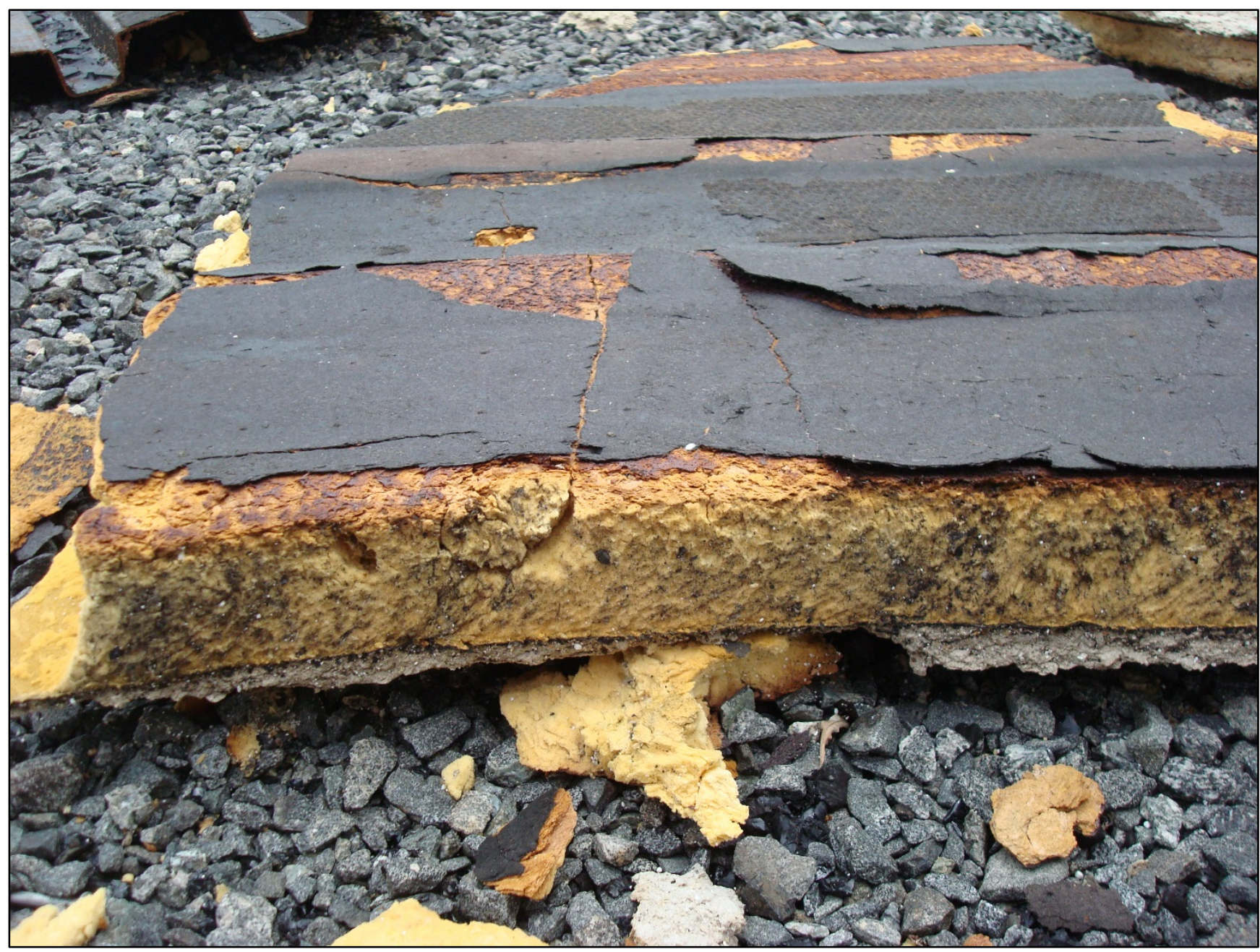

Photo 4. Photo shows close-up of asphalt and foam insulation covering metal roof deck. Note that the section of roof has been flipped upside down as a result of roof ventilation work.

(NIOSH photo.)

\section{Timeline}

Note: This timeline is provided to set out, to the extent possible, the sequence of events as the fire departments responded. The times are approximate and were obtained from review of the fire dispatch records, police dispatch records, witness interviews, and other available information collected by NIOSH. In some cases the times may be rounded to the nearest minute, and not all events have been included. The timeline is not intended, nor should it be used, as a formal record of events. 


\section{Volunteer Fire Fighter Dies After Running Out of Air and Becoming Disoriented in Retail Store in Strip Mall Fire-North Carolina}

- 2103 Hours

Local police respond for a security alarm activation and find smoke in a retail golf store in commercial strip mall.

- 2106 Hours

Department 7 and Department 2 dispatched for a commercial structure fire. Department 7 Engine 3, Ladder 1, and Fire Chief (in fire department chief's vehicle) responded along with Department 2 Engine 3.

- 2108 Hours

Department 7 Fire Chief arrives on-scene. Drives around structure and reports nothing showing.

- 2110 Hours

Department 7, Engine 3 arrives on-scene. Engine 3 fire fighters force front door and pull 13/4inch preconnect into the golf store.

- 2135 Hours

Mayday called by Engine 20 captain.

- 2143 Hours

Downed fire fighter removed from building.

- 2145 Hours

Downed fire fighter transported to hospital.

- 2200 Hours

Ambulance arrives at hospital.

- 2222 Hours

Fire fighter pronounced dead.

\section{Personal Protective Equipment}

At the time of this incident, the Engine 3 Fire Fighter 2 was wearing a full fire-fighting ensemble consisting of a turnout coat and pants, helmet, hood, gloves, and leather fire boots. He was wearing a station uniform consisting of a cotton T-shirt and station work pants. He carried a fire departmentissued portable radio and a flashlight was attached to the front of his turnout coat. He was wearing a self-contained breathing apparatus (SCBA) with an integrated PASS device. His radio was found to be turned on and set on the proper channel. 


\section{Volunteer Fire Fighter Dies After Running Out of Air and Becoming Disoriented in Retail Store in Strip Mall Fire-North Carolina}

Following the incident, the SCBA worn by Engine 3 Fire Fighter 2 along with the SCBA worn by the Engine 3 lieutenant, were transported to the NIOSH National Personal Protective Technology Laboratory in Morgantown, West Virginia, for evaluation and testing. A summary of the NIOSH evaluation is included in Appendix One. The full evaluation report is available upon request from the NIOSH National Personal Protective Technology Laboratory. The full evaluation report can also be downloaded from the NIOSH NPPTL PPE website https://www.cdc.gov/niosh/npptl/ppe-fireservice/pdfs/PinevilleFireDepartment20922.pdf.

\section{Weather Conditions}

The weather on April 30, 2016, at approximately 2100 hours was overcast with rain and thunderstorms in the area. The temperature was approximately 64 degrees Fahrenheit with 93 percent relative humidity and winds from the west/northwest at 6 miles per hour. Heavy thunderstorms had passed through the area approximately 1 hour prior to the fire being discovered. Investigators from the county fire marshal's office determined that the fire was likely caused by a lightning strike that hit the roof on Side Charlie near the Charlie/Delta corner of the building [Weather Underground 2016].

\section{Investigation}

On April 30, 2016, a 20-year-old male volunteer fire fighter died after he ran out of air and became disoriented while fighting a fire in a commercial strip mall. At 2106 hours, Department 7 (the local combination fire department) was dispatched for a fire in a commercial strip mall. A lightning storm had recently passed through the area. A lieutenant was working the night shift (2100 hours to 600 hours) at the station. Several volunteer members were also present at the station at the time of the dispatch. Department 2 was also dispatched for mutual aid.

Engine 3 responded from Department 7 with a total of six fire fighters on the apparatus. While en route, the fire fighters heard over the radio a city police officer confirm smoke in the building. Note: While en route, the lieutenant who was on duty and riding in the right rear jump seat dropped his portable radio on the floor of Engine 3. He felt underneath the seat and in the immediate area but could not locate the radio. When they arrived on-scene the crew immediately went to work. The lieutenant did not take time to continue searching for his radio. He did not have a portable radio when he entered the structure.

The Department 7 fire chief responded from his home in his fire department vehicle and drove past the front of the strip mall building to get a visual size-up of the exterior. He did not see any smoke on this initial drive around and radioed Dispatch that nothing was showing. He parked his fire department vehicle in front of the strip mall (Side Alpha) in the parking lot (see Photo 5) and assumed incident command. The city police department was already on-scene and established good traffic control. A police officer radioed that smoke was visible through the plate-glass front windows. The fire chief radioed the in-coming Engine 3 from Department 2 (automatic mutual aid) and directed them to reverse lay from Department 7 Engine 3 which was located at Side Alpha near the front door (see Photo 5), to the 


\section{Volunteer Fire Fighter Dies After Running Out of Air and Becoming Disoriented in Retail Store in Strip Mall Fire-North Carolina}

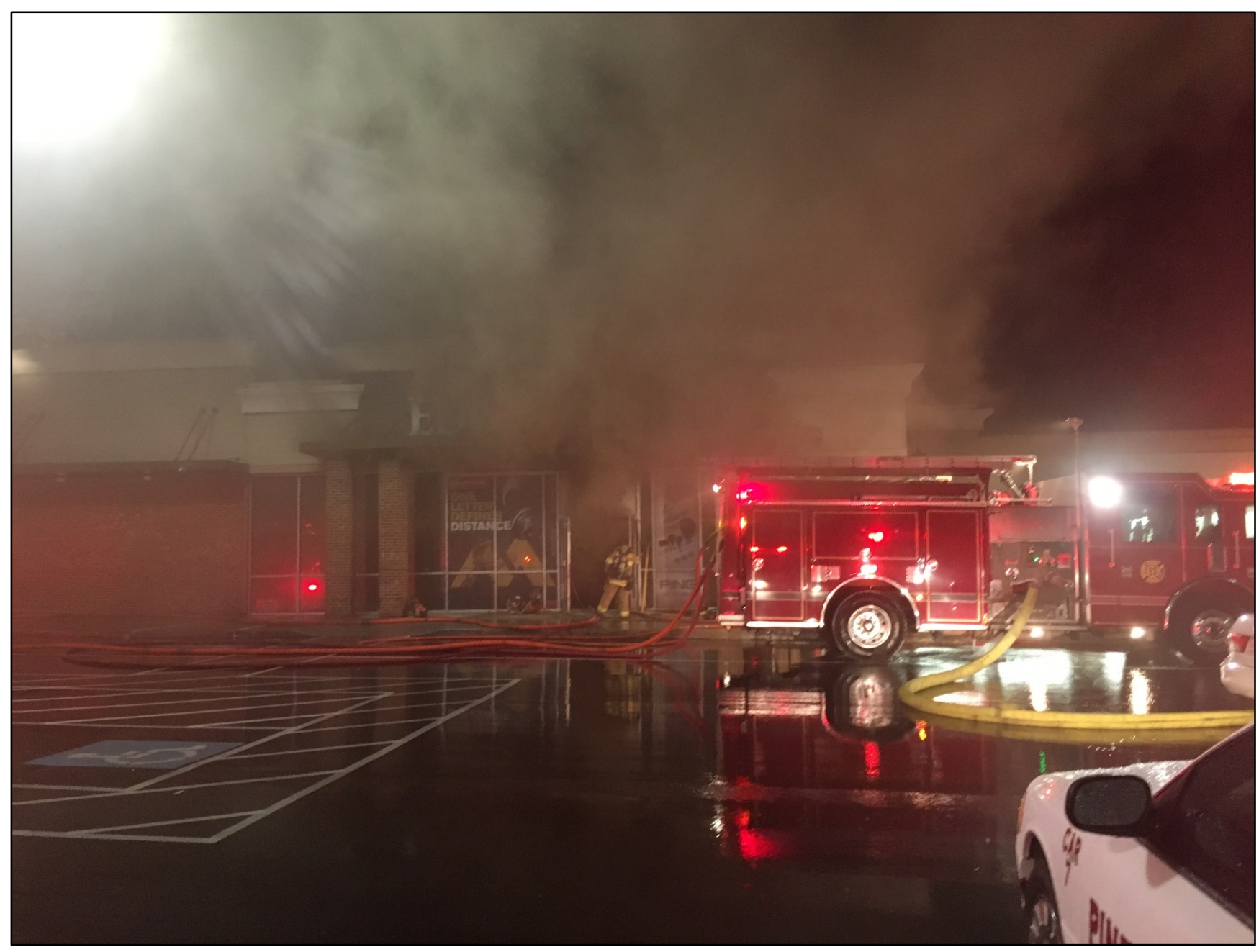

Photo 5. Location of Engine 3 and Chief's vehicle on Side A of fire building. (Photo courtesy of County Fire Marshal's Office.)

hydrant located east of the strip mall. When Engine 3 from Department 2 arrived with a captain and one fire fighter onboard, the fire chief ran to the engine and verbally directed them where to lay out their 5-inch supply line to supply water to Engine 3. The Department 2 engine supplied water to Department 7 Engine 3, which never ran low on water.

The fire chief radioed Dispatch and requested a first-alarm assignment from the city department (four engines, one ladder, one heavy rescue, one battalion chief). The Department 7 assistant chief radioed to the fire chief and reported that he was bringing the Department 7 ladder truck (Ladder 1) to the scene with one additional Department 7 fire fighter onboard. The city fire department Ladder 24 was in the area on a medical call and cleared the call, so the incident commander radioed county fire dispatch and requested that Ladder 24 be added to the assignment. Ladder 24 set up in the parking lot in front of the 


\section{Volunteer Fire Fighter Dies After Running Out of Air and Becoming Disoriented in Retail Store in Strip Mall Fire-North Carolina}

strip mall at Side Alpha. Note: The county fire dispatch system is able to provide a radio "patch" so that county fire departments can talk directly to city fire department units over the fireground channel.

The Engine 3 crew observed a light haze of smoke when they arrived in the strip mall parking lot. The Engine 3 senior captain, lieutenant, and Fire Fighter 2 approached the golf store door. Another fire department member arrived soon after in his privately owned vehicle (POV) and joined the Engine 3 crew. They quickly forced open the outer sliding plate-glass door and were confronted with an inner security gate door (see Photo 2). When the plate-glass door was opened, thick gray smoke rolled out of the store interior. The senior captain requested a power saw from Engine 3 to cut open the security gate. The lieutenant and senior captain from Department 7 continued to work on the security gate and were able to force open the security gate before the power saw was retrieved from Engine 3 . The captain directed the Engine 3 fire fighters to pull a 200-foot section of 13/4-inch preconnected hoseline to the front door while the lieutenant entered the structure a short distance and used a thermal imager to scan the interior. Additional units arrived on-scene. Department 7 Rescue Squad 8 arrived with two fire fighters and two junior fire fighters onboard. A total of five members of Department 7 arrived at the strip mall in their POVs. The lieutenant observed that the thermal imager was registering high heat at the rear of the store showroom near the Charlie/Delta corner. While the Engine 3 fire fighters stretched the hoseline to the front door, the lieutenant went back outside and reported to the captain that the fire appeared to be burning above the drop ceiling. The fire had burned through the drop ceiling but not through the roof. Two fire fighters and the senior captain advanced the hoseline inside the structure with the lieutenant directing them down the center isle using the thermal imager. A third fire fighter stayed at the front door and fed them the hoseline as they advanced. After they advanced inside about 10 feet they encountered thick light brown smoke banked down to the floor creating almost zero visibility. There was little to moderate heat inside the building.

The fire chief assigned the city Ladder 24 crew to perform roof ventilation work. The city battalion chief (Battalion Chief 5) arrived on-scene and assisted the Department 7 fire chief at the command post by setting up accountability. The Department 7 assistant chief arrived on-scene in Ladder 1 . The Department 7 assistant chief was assigned as the operations chief, and the Department 7 senior captain was in charge of suppression. The city fire department Engine 39 arrived on-scene and was assigned by Command (the Department 7 fire chief) to go to Side $\mathrm{C}$ and open the rear door. Note: The captain on Engine 39 was also the Department 2 assistant chief. The city fire department Engine 26 arrived on-scene and was directed by Command to assist Ladder 24 with roof ventilation. The city fire department Rescue 10 arrived and was also directed by Command to go to the roof. Note: The roof crews had difficulty cutting through the roof layers and the supporting metal roof deck (see Photo 3 and Photo 4).

The Department 7 assistant chief (operations chief) assembled a second hoseline crew of three Department 7 fire fighters and directed them to pull a second 13/4-inch preconnected hoseline from Engine 3 to the front door. Then he radioed Command and asked to get the back door opened to help with ventilation. The assistant chief also told the Engine 3 driver to make sure nobody broke out the storefront windows. 


\section{Volunteer Fire Fighter Dies After Running Out of Air and Becoming Disoriented in Retail Store in Strip Mall Fire-North Carolina}

The first hoseline crew advanced toward the Charlie/Delta corner and began to flow water toward the fire. The Engine 3 lieutenant used the thermal imager to direct the fire fighter working the nozzle on where to flow the water. The fire fighter on the nozzle ran low on air and became fatigued and passed the nozzle to Fire Fighter 2. The first fire fighter began to follow the hoseline outside after informing the lieutenant that he had to leave, but the senior captain was not advised that the fire fighter was leaving. The senior captain walked back toward the Bravo / Charlie corner to check for fire extension in that area. Fire Fighter 2 continued to work the nozzle with the lieutenant directing him with the thermal imager. The Engine 3 crew became aware of the roof crew from the career fire department working overhead to open the roof. Conditions continued to deteriorate inside the structure with increasing smoke and heat. Visibility was near zero.

The city fire department Engine 16 arrived on-scene followed by Engine 20. Engine 20 was assigned to assist Department 7 on the second $13 / 4$-inch preconnected hoseline pulled off Engine 3. Engine 16 was assigned by the operations chief to pull a 2 1/2-inch preconnected hoseline from Engine 3 to the front door.

At the front door, the Department 7 assistant chief directed the second hoseline crew from Department 7 to advance their hoseline inside. The assistant chief followed the first hoseline inside and the second hoseline crew followed the assistant chief. The assistant chief passed the fire fighter from the first hose line crew just inside the front door as the fire fighter was coming out and the assistant chief was following the first hoseline inside. The fire fighter told the assistant chief that he was low on air and they briefly discussed the conditions inside the structure. The assistant chief (operations) again radioed for the rear door to be opened to help with ventilation. The second $13 / 4$-inch preconnected hoseline was advanced about 40 feet into the center of the store when a coupling snagged on the doorframe at the front of the store. The crew on the second hoseline was unable to advance the hose so one of the crew members followed the hoseline back to the entrance to get more slack. Fire fighters at the door working to free the second 13/4 inch hoseline delayed Engine 16 in advancing the $2 \frac{1}{2}$-inch hoseline inside the structure. The Department 7 fire fighters working the second 13/4-inch hoseline ran low on air and had to follow their hoseline outside. The Engine 16 crew came to the nozzle on the second 13/4inch hoseline and decided to advance the 13/4-hoseline because it had more slack and would be easier to advance.

The Engine 3 Fire Fighter 2 ran low on air and his alarm began to go off. Fire Fighter 2 told the lieutenant that he needed to get out. The lieutenant tried to calm Fire Fighter 2 and took the nozzle and asked Fire Fighter 2 to hold the thermal imager up to the lieutenant's mask so he could locate the fire. While doing this, the hose stream hit the thermal imager and knocked it out of Fire Fighter 2's hand. Fire Fighter 2 again said he needed to get out. The senior captain and the lieutenant tried to calm him down. Fire Fighter 2 began following the line out but soon became separated from the line where it crossed over a display stand that held golf bags and ended up on the other side of a display case from where the lieutenant was operating the nozzle. Fire Fighter 2 bumped into the senior captain who told the fire fighter where to find the hoseline and directed the fire fighter to follow the hoseline out. The 


\section{Volunteer Fire Fighter Dies After Running Out of Air and Becoming Disoriented in Retail Store in Strip Mall Fire-North Carolina}

Department 7 assistant chief arrived at the nozzle and talked with the senior captain. The lieutenant's low-air alarm began to go off so the lieutenant told the assistant chief that he was going to go outside with Fire Fighter 2. The lieutenant directed Fire Fighter 2 to follow him on the hoseline.

Engine 39 forced open the rear door at Side C. Command directed Engine 39 to enter the structure through the rear door and start a primary search. Two ambulances arrived on-scene with an EMS supervisor.

The Engine 3 lieutenant followed the hoseline until he came to a coupling. He looked back for Fire Fighter 2 and saw that he was standing up. The lieutenant turned around and grabbed hold of Fire Fighter 2. They fell over a display of golf bags and became separated from the hoseline. The lieutenant turned in the direction that he thought was Side Alpha and began pulling Fire Fighter 2 with him. They were both walking in near-zero visibility when they ran into another display that consisted of racks of golf clubs. Fire Fighter 2 stated that he was completely out of air and had to get out of the building. The lieutenant was momentarily entangled in the golf clubs and became disoriented. Fire Fighter 2 disappeared into the thick smoke moving away from the lieutenant toward the rear of the store. The lieutenant also ran out of air and his facepiece fogged up, so he removed his helmet and facepiece in an effort to try to see so that he could orient himself. Note: The lieutenant's facepiece and helmet were found near the Side Charlie wall after the fire was extinguished (see Photo 6). The lieutenant activated his PASS device as he continued to crawl through a series of golf club displays. The lieutenant did not have a personal radio so he could not radio for assistance. He heard a voice in front of him (Engine 16 crew) and began to yell for help. The Department 7 assistant chief (Operations) radioed to Command that he could hear a PASS alarm going off. The Engine 16 driver radioed that he thought it was a fire alarm going off. The fire chief radioed for Engine 39 to investigate the PASS alarm.

The Engine 16 crew members saw the PASS device flashing lights and turnout reflective trim on the Engine 3 lieutenant who was approximately halfway inside the structure and near Side C. The Engine 3 lieutenant did not have his helmet or facepiece on. They quickly assisted him to the hoseline. One of the Engine 16 fire fighters stayed with the Engine 3 lieutenant all the way to the door.

The Engine 20 crew was assigned to assist with the second preconnected 13/4-inch hoseline off Engine 3. They arrived at the front door and observed that both hoselines were already deployed so they retrieved a rope bag from Engine 3 and deployed a search rope at the front entrance and began advancing inside the structure. They had advanced inside about 20 feet when they observed the Engine 3 lieutenant being assisted outside. One of the Engine 20 fire fighters helped assist the Engine 3 lieutenant to the front door. 


\section{Volunteer Fire Fighter Dies After Running Out of Air and Becoming Disoriented in Retail Store in Strip Mall Fire-North Carolina}

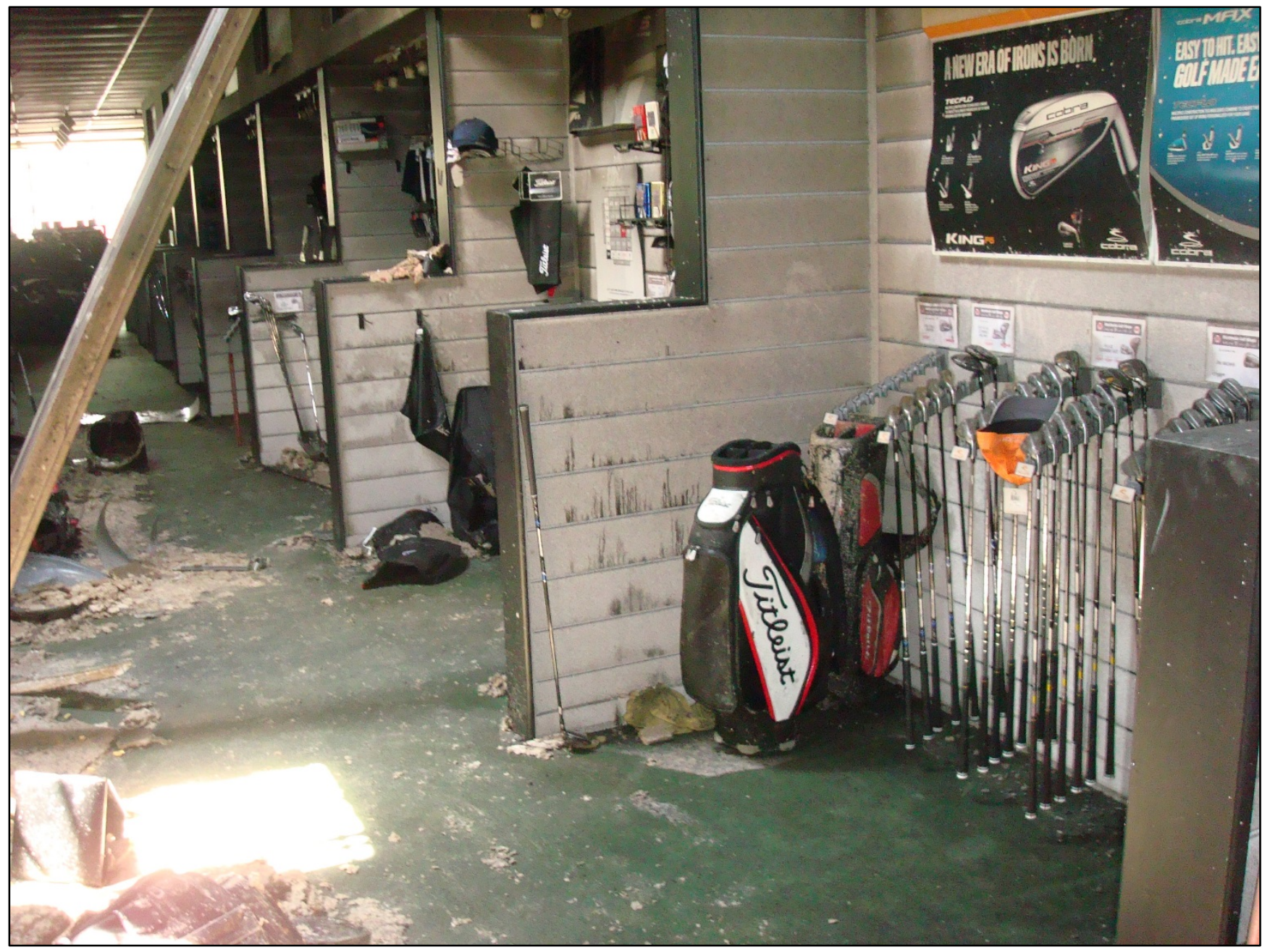

Photo 6. Photo shows U-shaped display racks built out from the Side Bravo wall that housed golf clubs and other golfing articles. The Engine 3 lieutenant reported becoming entangled in golf clubs in this area in near-zero visibility.

(Photo NIOSH.)

During this same time, the Engine 3 senior captain's low-air alarm went off. The Department 7 assistant chief (Operations) told the senior captain to follow the hoseline out and to send the lieutenant on the backup hoseline up to operate the nozzle. The senior captain began following the hoseline out. He briefly became stuck under a clothes rack and had to extricate himself. He was completely out of air when he made it outside.

When the Engine 3 lieutenant (out of air) arrived at the front entrance he was pulled outside by the Engine 3 driver. The lieutenant tried to tell fire fighters on the outside that the missing Engine 3 Fire 


\section{Volunteer Fire Fighter Dies After Running Out of Air and Becoming Disoriented in Retail Store in Strip Mall Fire-North Carolina}

Fighter 2 was still somewhere inside. The Department 7 fire chief (Command) observed the Engine 3 lieutenant crawling out the front door on his hands and knees at approximately 2140 hours.

The Engine 3 senior captain who had self-extricated from the structure, quickly changed his air cylinder and went back inside to assist with the search for the missing fire fighter.

The Engine 16 crew continued down the center of the store. They advanced in approximately 75 feet. The Engine 16 captain observed the golf club racks along the Side $C$ wall and then noticed a downed fire fighter through one of the display racks. The Engine 20 crew also continued its search in the golf store. One of the Engine 20 fire fighters heard a PASS device sounding and the Engine $20 \mathrm{crew}$ quickly assisted Engine 16 with the downed fire fighter. The Engine 3 Fire Fighter 2 was found with his facepiece and helmet on. He was completely out of air. The Engine 20 captain radioed a Mayday for a downed fire fighter. Dispatch directed the Mayday traffic to move to Fireground Tactical Channel 8 while the rest of the fireground communications remained on tactical channel 6. Note: When the change of tactical channels was made, the county fire dispatch center didn't establish the "patch" with the city fire department that would have enabled the two fire departments to communicate directly on the new channel. Approximately 2 minutes later, Engine 3 Fire Fighter 2 was pulled outside by the Engine 16 and Engine 20 crews. The EMS supervisor told Command that two fire fighters were being evaluated.

The fire was reported under control at 2157 hours.

Engine 3 Fire Fighter 2 exhibited weak agonal breathing and was cyanotic. Advanced life support measures were immediately initiated. Engine 3 Fire Fighter 2 was transferred onto a stretcher and loaded into an ambulance. Following locally established treatment protocols, he was transported Priority 1 to a trauma hospital in the city approximately 15 minutes away, bypassing the closest community hospital that was about 2 minutes from the strip mall. The Engine 3 Fire Fighter 2 went into cardiac arrest while en route. Cardio-pulmonary resuscitation (CPR) was immediately initiated on Engine 3 Fire Fighter 2 while en route to the hospital. After the Engine 3 Fire Fighter 2 was removed from the structure, the Fire Chief (Command) started a personal accountability report (PAR) but a phone call from one of the paramedics notifying the Fire Chief that the Engine 3 Fire Fighter 2 was in critical condition interrupted the PAR and the PAR was never completed. The Engine 3 Fire Fighter 2 was pronounced dead at the hospital at 2222 hours. The Engine 3 lieutenant was transported to the hospital and treated and released later in the day.

Note: This was the first working fire that the Engine 3 Fire Fighter 2 had made entry as part of a hoseline crew and worked the nozzle. 


\section{Volunteer Fire Fighter Dies After Running Out of Air and Becoming Disoriented in Retail Store in Strip Mall Fire-North Carolina}

\section{Fire Behavior}

The county fire marshal's office fire investigators determined that the fire was accidential in nature and was likely caused by lightning striking the roof of the retail golf store near the Side Charlie/Delta corner (at the rear) and igniting the asphalt-based roofing materials covering the metal roof deck. Investigators from the county fire marshal's office were able to eliminate all identifiable and potential ignition sources during their fire scene examination.

Key factors related to fire behavior and development in this incident include the following:

- $\quad$ Severe thunder and lightning storms moved through the area at approximately 2000 hours.

- Police responded to the incident scene at approximatley 2103 hours for an alarm activation.

- Police officer observed light smoke around light fixtures outside the structure.

- Fire department dispatched at 2106 hours for report of a commercial structure fire.

- Fire department initially reported nothing showing then reported a working fire at 2111 hours.

- Fire department forced entry at front entrance.

- Thick, gray smoke rolled out of the store interior when the plate-glass door was opened.

- The lieutenant entered into the store a short distance, and using a thermal imager, was able to observe high heat in the rear of the structure at the Charlie/Delta corner.

- The initial hoseline crew advanced inside about 10 feet and encountered thick, light brown smoke banked down to the floor, creating almost zero visibility.

- Little to moderate heat was reported inside the building.

- The hoseline crew used a thermal imager to locate the fire overhead near the Charlie/Delta corner.

- Operations chief requested rear door be opened to aid ventilation.

- Roof crews experienced difficulty in cutting through metal roof deck (see Photo 3 and Photo 4).

- Crews continued to work in near-zero visibility conditions.

- Fire burning in the void space above the drop-down ceiling.

- Fire brought under control at 2157 hours.

- Evidence shows a combustible metal deck roof fire (see Photo 7). 
Volunteer Fire Fighter Dies After Running Out of Air and Becoming Disoriented in Retail Store in Strip Mall Fire-North Carolina

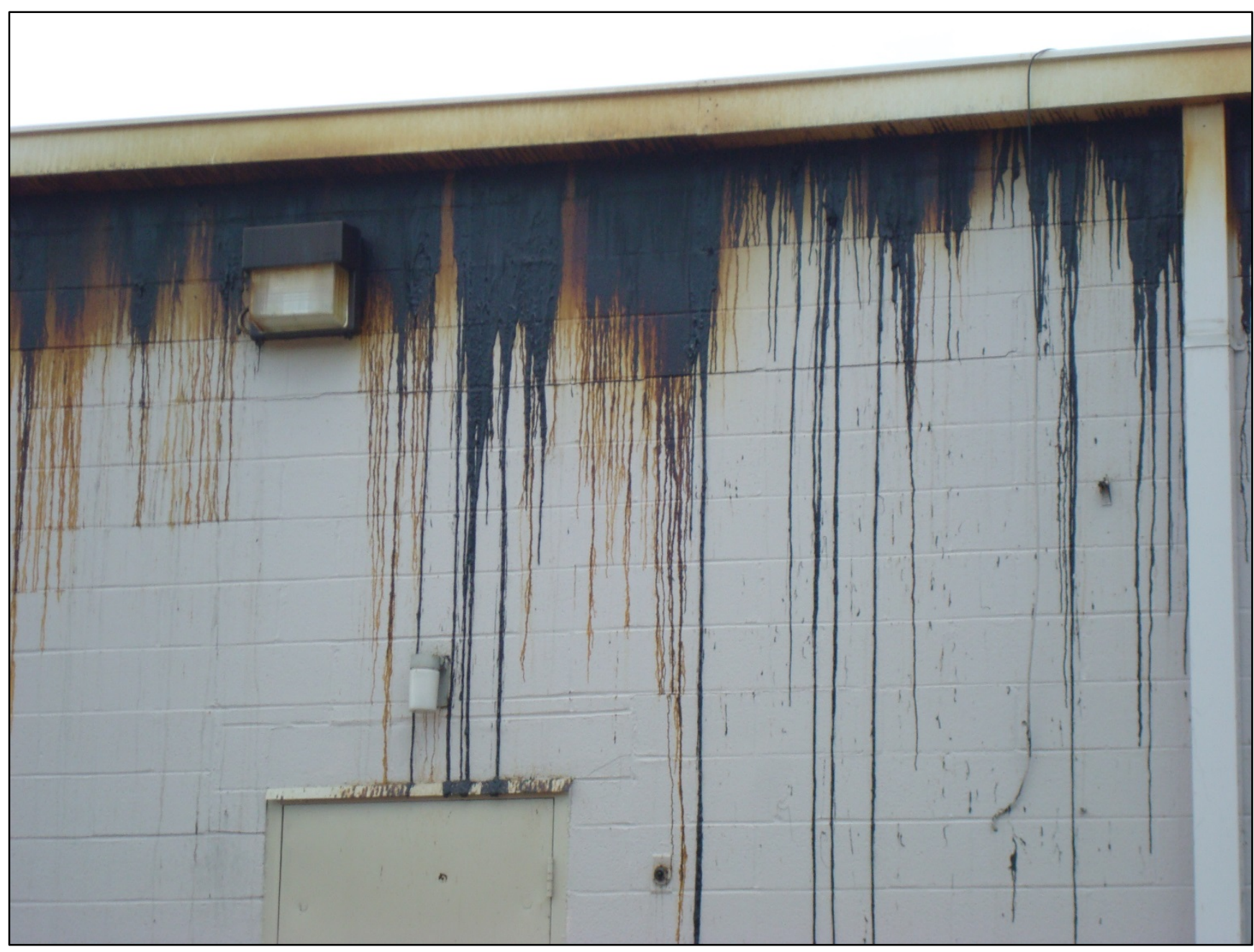

Photo 7. Side $C$ exterior wall above the rear entrance door. Note the melted asphalt that ran down exterior wall from the roof. This is consistent with a combustible metal deck roof fire. (NIOSH photo.)

\section{Contributing Factors}

Occupational injuries and fatalities are often the result of one or more contributing factors or key events in a larger sequence of events that ultimately result in the injury or fatality. NIOSH investigators identified the following items as key contributing factors in this incident that ultimately led to the fatality:

- Lack of crew integrity

- Inadequate air management training 
- Inexperienced fire fighter

- Ineffective fireground communications

- Failure to call a Mayday in a timely manner

- No sprinkler system in commercial structure.

- Zero-visibility conditions in smoke-filled retail store

- Restricted mobility due to arrangement of floor displays.

\section{Cause of Death}

According to the medical examiner's report, the cause of death was inhalation of products of combustion due to "fire fighter in structure fire." The manner of death was listed as accidental.

\section{Recommendations}

Recommendation \#1: Fire departments should ensure that crew integrity is properly maintained by sight, voice, or radio contact when operating in an immediately-dangerous-to-life-or-health (IDLH) atmosphere.

Discussion: Crews of fire fighters should operate as cohesive teams of at least two and remain in contact by visual (eye-to-eye contact), verbal (by radio or by person-to-person), or direct (by touch) contact when entering a structure or potentially hazardous area. NFPA 1500 Standard on Fire Department Occupational Safety and Health Program states in Paragraph 8.5.5, "Crew members operating in a hazardous area shall be in communication with each other through visual, audible, or physical means or safety guide rope, in order to coordinate their activities” [NFPA 2013c]. Additionally, NFPA 1500 Paragraph 8.5.6 states, "Crew members shall be in proximity to each other to provide assistance in case of an emergency" [NFPA 2013c]. The Occupational Safety and Health Administration (OSHA), Title 29, Code of Federal Regulations (CFR), Part 1910.134(g)(4)(i) requires that at least two fire fighters enter an IDLH environment together and remain in visual or voice contact with each other at all times [OSHA 1998].

The International Association of Fire Chiefs, Safety, Health, and Survival Section has defined a set of Rules of Engagement for Structural Fire-Fighting, based on nationally recognized best practices. One of the objectives is to ensure that fire fighters always enter a burning building as a team of two or more members and no fire fighter is allowed to be alone at any time while entering, operating in, or exiting a building. A critical element for fire fighter survival is crew integrity. Crew integrity means fire fighters stay together as a team of two or more. They must enter a structure together and remain together at all times while in the interior, and all members come out together. Crew integrity starts with the company officer ensuring that all members of the company understand their riding assignment, have the proper 


\section{Volunteer Fire Fighter Dies After Running Out of Air and Becoming Disoriented in Retail Store in Strip Mall Fire-North Carolina}

personal protective equipment, and have the proper tools to perform their job. Crew integrity continues upon arrival at the incident, where the incident commander assigns tasks. The company officer communicates to the members of the company what their assignment is and how they will accomplish the assignment. Members of a company enter a hazardous environment together and should leave together to ensure that crew integrity is maintained. If one member has to leave, the whole company leaves together [IAFC 2012].

Every fire fighter is responsible for staying in communication with other crew members at all times. All fire fighters must maintain the unity of command by operating under the direction of the incident commander, division/group supervisor, or their company officer at all times. The ultimate responsibility for crew integrity (functioning as a team, ensuring no members get separated or lost) at the company level rests with the company officer. They must maintain constant contact with their assigned members by visual observation, voice, or touch while operating in a hazard zone. They must ensure they stay together as a company or crew. If any of these elements are not adhered to, crew integrity is lost and fire fighters are placed at great risk. If a fire fighter becomes separated and cannot re-connect with his/her crew immediately, the fire fighter must attempt to communicate via portable radio with the company officer. If reconnection is not accomplished after three radio attempts or reconnection does not take place within 1 minute, a Mayday should be declared. If conditions are rapidly deteriorating, the Mayday must be declared immediately. As part of a Mayday declaration, the fire fighter must next activate the radio's emergency alert button (where provided), followed by manually turning on the PASS alarm. Similarly, if the company officer or the fire fighter's partner recognizes they have a separated member, they must immediately attempt to locate the member by using their radio or by voice. A Mayday must be declared immediately if contact is not established after three attempts or within 1 minute [IAFC 2012]. Most importantly, a Mayday can be declared by any member operating on the incident scene once they become aware that they, or any other member is in danger and in need of assistance.

The fire department involved in this incident had standard operating procedures in place at the time of this incident that stressed maintaining crew integrity. In this incident, Engine 3 Fire Fighter 2 ran low on air and stated that he needed to get out of the building. His crew members attempted to calm him down. He began to follow the hoseline out but soon became separated from the hoseline. When the Engine 3 lieutenant also ran low on air, he told the assistant chief that he would lead the Engine 3 Fire Fighter 2 outside. While following the hoseline, the Engine 3 lieutenant looked back to see where the Engine 3 Fire Fighter 2 was and observed Engine 3 Fire Fighter 2 stand up and move away from the hoseline. The lieutenant tried to catch the Fire Fighter 2 but they both ended up separated from the hoseline. The lieutenant became disoriented and needed to be rescued by another crew. During this incident, there were a number of other reported instances where crew integrity was not maintained. Fire fighters were reported to be alone while searching for fire, operating hoselines and following hoselines outside. Near-zero visibility within the structure also contributed to the fire fighters becoming separated from crew members. 


\section{Volunteer Fire Fighter Dies After Running Out of Air and Becoming Disoriented in Retail Store in Strip Mall Fire-North Carolina}

\section{Recommendation \#2: Fire departments should ensure all fire fighters are trained on and actively practice air management principles.}

Discussion: Chief Bobby Halton, retired fire chief and current editor-in-chief of Fire Engineering notes: "If you run out of air in a working fire today, you are in mortal danger. There is no good air at the floor anymore, no effective filtering methods, no matter what others may say to the contrary." The only protection for fire fighters in the toxic smoke environments in today's fires is the air that they carry on their backs. Like SCUBA divers, fire fighters must manage their air effectively to leave enough reserve air to escape in case of unforeseen occurrences while inside a structure fire. Fire fighters must manage their air so that they leave the immediately-dangerous-to-life-or-health (IDLH) atmosphere before the low-air alarm activates. This leaves an emergency air reserve and removes the noise of the low-air alarm from the fireground [Gagliano et al. 2008]. Air management is a program that the fire service can use to ensure that fire fighters have enough breathing air to complete their primary mission and to escape an unforeseen emergency. Fire departments and fire fighters need to recognize that the smoke in modern construction is an IDLH atmosphere and manage their air along with their work periods so the fire fighters exit the IDLH atmosphere with their reserve air intact. NFPA 1404 Standard for Fire Service Respiratory Protection Training states that fire fighters should exit from an IDLH atmosphere before the consumption of reserve air supply begins; a low-air alarm is notification that the individual is consuming the reserve air supply and activation of the reserve air alarm requires immediate action of the individual and the fire-fighting team [NFPA 2013b].

A low-air alarm is a fireground emergency and should be treated accordingly. A crew of fire fighters who enter an IDLH environment together can be expected to run low on air in rapid sequence as experienced in this incident. At least three members of the initial attack crew ran completely out of air, resulting in one death with two other fire fighters who needed assistance and could have easily been fatalities. A low-air emergency for one crew member should be treated as an emergency for the entire team, requiring the entire team to exit simultaneously, maintaining crew integrity.

The vast majority of the structure fires responded to are single- or multi-family residential occupancies. For some fire departments, a typical strategy is an aggressive offensive fire fight to achieve the tactical priorities. Generally, fire crews are able to search these structures quickly, put out the fire, and exit the hazard zone without having to give much thought to air management. Multiple points of egress are usually close by should a rapid retreat to the exterior become necessary. High-rise apartment buildings, commercial structures, and large open floor plan mansions present additional challenges that fire fighters must consider.

It's critical to ensure fire fighters exit the hazard zone with an emergency reserve of air. According to NFPA 1404, "all members using an SCBA in the hazard zone of an incident shall monitor the amount of air in their SCBA cylinder as well as their rate of air consumption in order to exit the hazard zone prior to the low-air alarm activation of the SCBA" [NFPA 2013b]. Just as ocean divers are trained to surface with an emergency reserve of air, fire fighters shall exit the hazard zone of an incident with an emergency reserve of air. It is critical that fire fighters understand that the initial $67 \%$ of the air supply 


\section{Volunteer Fire Fighter Dies After Running Out of Air and Becoming Disoriented in Retail Store in Strip Mall Fire-North Carolina}

is the "working and exiting air" [NFPA 2013b]. This includes air used for gaining access, working toward the tactical objectives, and exiting the hazard zone.

Company officers should frequently assess their crew's air consumption rates and decide the crew's exit time based on the individual with the greatest assumed air consumption rate. It is the individual fire fighter's responsibility to continually assess and report his/her air consumption to his/her company officer.

In this incident, three members of the initial hoseline crew from Engine 3 ran completely out of air before exiting the smoke-filled store interior. Engine 3 Fire Fighter 2, the lieutenant, and the senior captain all ran low on air and started to exit the burning golf store after their low-air alarms went off. The Engine 3 Fire Fighter 2 ran low on air while working the attack hoseline nozzle. The lieutenant and senior captain tried to calm down the less-experienced fire fighter. As the lieutenant and fire fighter attempted to follow the hoseline out, they became separated. The senior captain and lieutenant reported that their SCBA air cylinders ran completely out of air before they exited the building. The lieutenant had to be treated for smoke inhalation and was transported to the hospital for medical attention. Engine 3 Fire Fighter 2 was not able to exit the building after he ran completely out of air. All of this occurred after the Engine 3 Fire Fighter 1 ran low on air and successfully self-extricated alone. In this case, the entire crew should have exited together when the first fire fighter ran low on air which was a valid warning that all of the Engine 3 crew would run low on air in rapid succession.

\section{Recommendation \#3: State, local, and municipal governments, building owners, and authorities having jurisdiction should consider requiring the use of sprinkler systems in commercial structures.}

Discussion: This recommendation focuses on fire prevention and minimizing the impact of a fire if one does occur. The National Fire Protection Association (NFPA) Fire Protection Handbook states: "Throughout history there have been building regulations for preventing fire and restricting its spread. Over the years these regulations have evolved into the codes and standards developed by committees concerned with fire protection. The requirements contained in building codes are generally based upon the known properties of materials, the hazards presented by various occupancies, and the lessons learned from previous experiences, such as fire and natural disasters” [NFPA 2008]. Although municipalities have adopted specific codes and standards for the design and construction of buildings, structures erected prior to the enactment of these building codes may not be compliant. Such new and improved codes can improve the safety of existing structures [NFPA 2008]. Sprinkler systems are one example of a safety feature that can be retrofitted into older structures. Sprinkler systems can reduce fire fighter and civilian fatalities since such systems can contain and may even extinguish fires prior to the arrival of the fire department.

Fire development beyond the incipient stage is one of the greatest hazards that fire fighters face in today's combustible environment. This exposure and risk to fire fighters can be dramatically reduced when fires are controlled or extinguished by automatic sprinkler systems. NFPA statistics show that most fires in sprinklered buildings are controlled prior to fire department arrival by the activation of 
Volunteer Fire Fighter Dies After Running Out of Air and Becoming Disoriented in Retail Store in Strip Mall Fire-North Carolina

one or two sprinkler heads. The presence of automatic fire sprinklers also reduces the exposure risk to fire fighters in rescue situations by allowing the safe egress of building occupants before the fire department arrives on-scene. Finally, the exposure to hazards such as building collapse and overhaul operations are greatly reduced, if not eliminated, when fire development is arrested and controlled.

The commercial strip mall involved in this incident was constructed in 1978. The fire and building codes at that time did not require a sprinkler system. The fire started due to a lightning strike to the roof. The fire burned in the void space between the metal roof deck and the drop ceiling for some time. While a sprinkler system in the golf store protecting the store contents would not have initially contained the fire, a quick-action sprinkler system in the void space above the drop ceiling would have significantly reduced the risk to all by containing the fire to the area of origin, if not extinguished the fire completely.

Recommendation \#4: Fire departments should define fireground strategy and tactics for an occupancy that are based upon the organization's standard operating procedures. Incident commanders should base the strategy and tactics on the community risk assessment, building occupancy, pre-incident planning, critical building information system, staffing, and available resources.

Discussion: Since no two fire departments are alike, there is no standard scale to measure and evaluate frequency and severity of risk. Some fire departments will have a greater or lesser degree of tolerance for risk than others. The intent of the risk management process is for a fire department to develop a standard level of safety. This standard level of safety defines the parameters of the acceptable degree of risk for which members perform their job functions.

By definition, frequency is how often something does, or might, happen. Severity (risk) is a measure of the consequences if an undesirable event occurs (see Figure 1). Each risk will have its own set of factors that will dictate how a fire department will try to determine how severe the consequences might be. This scale is used to establish the degree of priority. Priority of the risk is in direct relation to inherent risks that have had a harmful effect on a fire department and its members [NFA 2004]. 
Volunteer Fire Fighter Dies After Running Out of Air and Becoming Disoriented in Retail Store in Strip Mall Fire-North Carolina

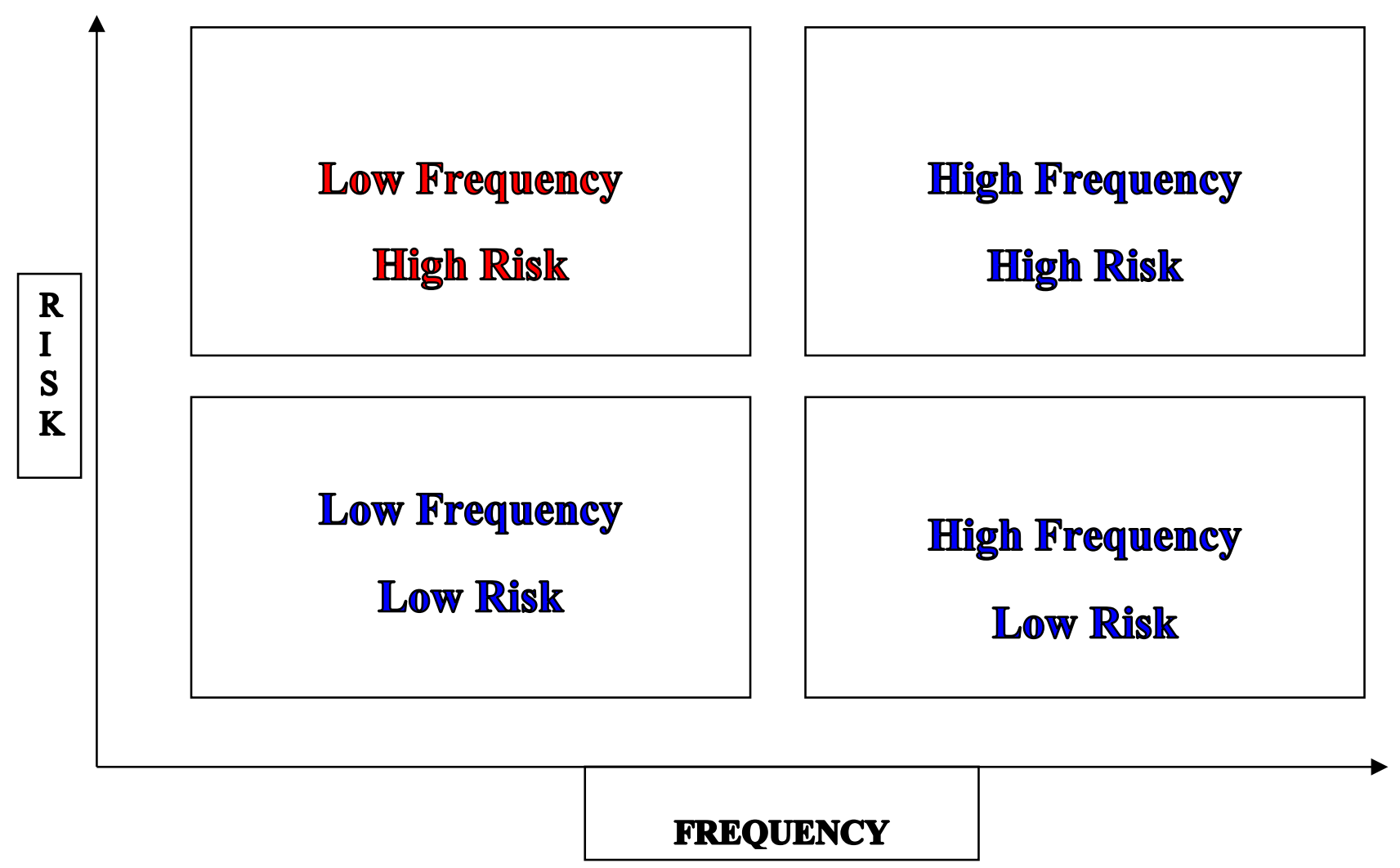

Figure 1.

Risk versus Frequency. Low frequency, high risk events can be especially hazardous to fire fighters and emergency responders.

In this incident, the fire department responded to a working fire in a commercial strip mall. A working fire in a commercial strip mall is a low frequency event with high risk to fire fighters due to construction features that limit ingress and egress. The fire department did not have a pre-incident plan for this structure.

Recommendation \#5: Fire departments should conduct pre-incident planning inspections of buildings within their jurisdictions to facilitate development of safe fireground strategies and tactics.

Discussion: National Fire Protection Association (NFPA) 1620 Standard for Pre-Incident Planning, 2015 Edition, A.4.1.1 states, "a pre-incident plan is one of the most valuable tools available for aiding responding personnel in effectively controlling an emergency." The pre-incident plan is defined as “a document developed by gathering general and detailed data that is used by responding personnel in 


\section{Volunteer Fire Fighter Dies After Running Out of Air and Becoming Disoriented in Retail Store in Strip Mall Fire-North Carolina}

effectively managing emergencies for the protection of occupants, responding personnel, property, and the environment [NFPA 2015]. A pre-incident plan identifies deviations from normal operations and can be complex and formal, or simply a notation about a particular problem, such as the presence of flammable liquids, explosive hazards, modifications to structural building components, or structural damage from a previous fire [Dunn 2007, NFPA 2015, NIOSH 1999].

In addition, NFPA 1620 outlines the steps involved in developing, maintaining, and using a preincident plan by breaking the incident down into pre-, during- and post-incident phases. In the preincident phase, for example, it covers factors such as physical elements and site considerations, occupant considerations, protection systems and water supplies, hydrant locations, and special hazard considerations. Building characteristics including type of construction, materials used, occupancy, fuel load, roof and floor design, and unusual or distinguishing characteristics should be recorded, shared with other departments who provide mutual aid, and if possible, entered into the dispatcher's computer so that the information is readily available if an incident is reported at the noted address. Since many fire departments have tens and hundreds of thousands of structures within their jurisdiction, making it impossible to pre-plan them all, priority should be given to those having elevated or unusual fire hazards and life safety considerations. Additionally, it is important to note that strategies and tactics employed at the emergency incident need to match the structure. The pre-plan information can be used to help ensure that residential fire tactics are not applied at commercial structures.

In this incident, the fire department had not conducted a formal pre-plan inspection at the structure.

\section{Recommendation \#6: Fire departments should train company officers and fire fighters to report interior conditions to the incident commander as soon as possible and on a regular basis.}

Discussion: Proper size-up and risk-versus-gain analysis requires that the incident commander (IC) has a number of key pieces of information and be kept informed of the constantly changing conditions on the fireground. The IC must develop and utilize a system that captures pertinent incident information to allow continuous situational evaluation, effective decision making, and development of an incident management structure. Decisions can be no better than the information on which they are based. The IC must use an evaluation system that considers and accounts for changing fireground conditions in order to stay ahead of the fire. If this is not done, the incident action plan (IAP) will be out of sequence with the phase of the fire, and the IC will be constantly surprised by changing conditions [Brunacini 1985; Dunn 1988; NIOSH 1999]. Interior size-up is just as important as exterior size-up. Since the IC is staged at the command post (outside), the interior conditions should be communicated to the IC by interior crews as soon as possible. Interior conditions could change the IC's strategy or tactics. Interior crews can aid the IC in this process by providing reports of the interior conditions as soon as they enter the fire building and by providing regular updates. According to Chief Dunn, construction features discovered in a commercial structure should be immediately communicated to the IC. An example would be drop ceilings and other features that could hide void spaces [Dunn 1988]. Also, NFPA 1500, Chapter 8.2, Communications, section 8.2.1, states that the fire 


\section{Volunteer Fire Fighter Dies After Running Out of Air and Becoming Disoriented in Retail Store in Strip Mall Fire-North Carolina}

department shall establish and ensure the maintenance of a fire dispatch and incident communications system that meets the requirements of NFPA 1561 Standard on Emergency Services Incident Management and Command Safety [NFPA 2014] and NFPA 1221 Standard for the Installation, Maintenance, and Use of Emergency Services Communications Systems [NFPA 2013c].

Chief Brunacini states that critical fireground factors, including interior and exterior conditions, are among the many items that the IC must consider when evaluating tactical situations. These items provide a checklist of the major topics involved in size-up, decision making, initiating operations, and review and revision. The IC deals with these critical factors through a systematic management process that creates a rapid, overall evaluation; sorts out the critical factors in priority order; and then seeks out more information about each factor. The IC must train and prepare (through practice) to engage in conscious information management. Incident factors and their possible consequences offer the basis for a standard incident-management approach. A standard information approach is the launching pad for effective incident decision making and successful operational performance. The IC must develop the habit of using the critical factors in their order of importance as the basis for assigning the specific assignments that make up the IAP. The IC must create a standard information system and use effective techniques to keep informed at the incident. The IC can never assume the action-oriented responder engaged in operational activities will stop what they are doing so they can feed the IC with a continuous supply of top-grade objective information. It is the IC's responsibility to do whatever is required to stay effectively informed [Brunacini 2011]. One effective strategy for obtaining important incident-critical information is to utilize a "Conditions-Actions-Needs" or "CAN" report. This allows the incident commander to call an interior officer and request a CAN report, prompting the officer to respond in a standardized manner with crucial intelligence that contributes to the IC's ability to make informed decisions.

During this incident, roof crews reported conditions observed on the roof and this information was considered by the IC and company officers at the scene. However, no interior condition reports were broadcast over the radio (to the chief officers or other fire fighters) during this incident. Verbal exchanges between the interior crews and company officers took place, but this information did not reach the incident commander to help make tactical decisions in fighting the fire.

\section{Recommendation \#7: Fire departments should ensure that an initial risk assessment is performed and continuous risk assessment is accomplished throughout the incident and the strategy and tactics match the conditions encountered.}

Discussion: A risk management plan ensures that the risks are evaluated and matched with the actions and conditions. At any incident, life safety is always the first priority, followed by incident stabilization (second priority) and then property conservation (third priority). The ability to ensure for the safety of fire fighters is a continuous process throughout the incident. The following risk management principles should be utilized by incident commanders: 


\section{Volunteer Fire Fighter Dies After Running Out of Air and Becoming Disoriented in Retail Store in Strip Mall Fire-North Carolina}

- Activities that present a significant risk to the safety of fire fighters should be limited to situations that have the potential to save endangered lives.

- Activities that are routinely employed to protect property should be recognized as inherent risks to the safety of fire fighters, and the actions should be taken to reduce or avoid these risks.

- No risk to the safety of fire fighters should be acceptable where there is no possibility to save lives or property [Brunacini 2002].

The strategy and tactics of an incident are dictated by the size-up, initial risk assessment, and initial report by the first arriving officer. As in this case, and at every structure fire, it is a priority that a 360degree size-up is included in the risk assessment. Life hazard, fire extent and location, and building conditions are factors that need to be a part of the size-up and help to match the strategy and tactics with the conditions encountered and this information must be continual. If a 360 degree walk around cannot be completed, then a size-up of the areas can be accomplished through the assignment of personnel and apparatus to divisions starting with a priority of Division $\mathrm{C}$ or the rear of the building.

The incident commander is responsible for evaluating conditions at a structure fire and determining the strategy and tactics for fighting the fire. In many cases the first arriving officer is the initial incident commander and sets in motion the strategy and tactics. Command is later passed to a higher-level officer and a formal command is established. The incident commander needs to ensure that the strategy and tactics are appropriate with all of the size-up factors. To accomplish this, the incident commander should use a standardized strategic decision-making model.

First, the incident commander should size up the critical fireground factors [PFD 2009]. Before ordering an offensive attack, the incident commander must make a determination that offensive (interior) operations may be conducted without exceeding a reasonable degree of risk to fire fighters and must be prepared to discontinue the offensive attack if the risk evaluation changes during the firefighting operation. A full range of factors must be considered in making the risk evaluation, including the following:

- Presence of occupants in the building

- A realistic evaluation of occupant survivability and rescue potential

- Size, construction, and use of the building

- Age and condition of the building

- Nature and value of building contents

- Location and extent of the fire within the building

- Adjacent exposures (structures)

- Fire involvement or compromise of the building's structural components

- Residential or commercial structure

- Delayed discovery/reporting and its effect on burn time and structural stability

- Considerations of fire loading and fire behavior 


\section{Volunteer Fire Fighter Dies After Running Out of Air and Becoming Disoriented in Retail Store in Strip Mall Fire-North Carolina}

- A realistic evaluation of the ability to execute a successful offensive fire attack with the resources that are available [PFD 2009; NIOSH 2010].

These fireground factors should be weighed against the risk management plan. Fire fighters are routinely exposed to certain known and predictable risks while conducting operations that are directed toward saving property. The incident commander is responsible for recognizing and evaluating those risks and determining whether the level of risk is acceptable or unacceptable. However, risks taken to save property should always be less than those to save lives [Grorud 2009; NIOSH 2010]. Risks to fire fighters versus gains in saving lives and property should always be considered when deciding whether to use an offensive or defensive attack.

The incident commander should continually match the actions against the conditions based upon continuous reports from all operating companies. This gives the incident commander the ability to control the situation by forecasting and staying ahead, rather than the fire dictating the actions taken. The incident commander should routinely evaluate and re-evaluate conditions and radio progress reports in reaching objectives to Dispatch and on-scene fire fighters. This process allows the incident commander to determine whether to continue or revise the strategy and attack plans. Failure to revise an inappropriate or outdated attack strategy is likely to result in an elevated risk of death or injury to fire fighters [NFPA 2013c; PFD 2009].

The risk assessment of a building during fire-fighting operations should be continuous with building intelligence and reconnaissance communicated on degrading conditions, fire extension and compromise, building integrity considerations, the effects of fire spread and suppression on the interior compartment(s), and the structural system and building envelope.

It is important that fire officers and fire fighters understand risk management principles and apply that knowledge to modern fire conditions, especially in commercial structures.

In this incident, the fire department responded at 2106 hours on a Sunday evening to a fire in a commercial strip mall. The front door and security gate were locked and had to be forced open to gain access to the structure. The fire chief drove around the structure to get a full view of the building and then established command in the parking lot at Side A. The crews entering the structure reported nearzero visibility. The locked doors, time of day, the weekend, and few cars in the parking lot suggested that the building was likely unoccupied. It is important to note that the building becomes an "occupied structure" when the incident commander permits fire fighters to enter it for extinguishment purposes. The decision to allow fire fighters to enter a burning building should be a calculated one based upon available information, not an automatic response. The IC should have a plan (and resources) in place to quickly and effectively remove fire fighters from the structure before allowing them to commit deeply into a fire fight. 


\title{
Volunteer Fire Fighter Dies After Running Out of Air and Becoming Disoriented in Retail Store in Strip Mall Fire-North Carolina
}

\begin{abstract}
Recommendation \#8: Fire fighters and officers should ensure critical benchmarks, such as progress or lack of progress, are communicated to the incident commander and that positive communication disciplines are used.
\end{abstract}

Discussion: Fire officers and fire fighters need to understand that communicating benchmarks is critical and radio communications are often difficult to hear and/or understand. Effective communication involves a thorough understanding of the message. The sender transmits a clear message and the receiver must acknowledge the transmission so the sender knows that the transmission was understood.

Retired Fire Chief Alan Brunacini states that critical fireground factors, including interior and exterior conditions, are among the many items that the incident commander must consider when evaluating tactical situations. These items provide a checklist of the major issues involved in size-up, decision making, initiating operations, and review and revision. The incident commander deals with these critical factors through a systematic management process that creates a rapid, overall evaluation; sorts out the critical factors in priority order; and then seeks out more information about each factor. The incident commander should train and prepare (through practice) to engage in conscious information management. Incident factors and their possible consequences offer the basis for a standard incident management approach. A standard information approach is the launching pad for effective incident decision making and successful operational performance. The incident commander should develop the habit of using the critical factors in their order of importance as the basis for making the specific assignments that make up the incident action plan. The incident commander should create a standard information system and use effective techniques to keep informed at the incident. The incident commander can never assume the action-oriented responder engaged in operational activities will stop what they are doing so they can feed the incident commander with a continuous supply of objective information. It is the incident commander's responsibility to do whatever is required to stay effectively informed [Brunacini 2002].

When using radio communication the sender and receiver are only using one of the human senses (hearing) to communicate. Effective communication is always better when you can use more of the human senses to communicate. This is not always practical or possible on the fire ground and it is why positive communication discipline is required to close the communication loop. It is not a complicated process, but frequently overlooked (positive feedback from the receiver). If the sender communicates a message and the receiver doesn't provide a disciplined feedback response, the sender may assume his/her message was understood, when in fact it may never have been received or understood.

Another key point with benchmark communications is that the back and forth communications aids the incident commander and any accountability officers on the fireground with important accountability information such as the location and status of the crew providing the interior information. In this incident, critical benchmark information was not communicated in a standardized manner. Critical benchmarks that should be communicated over the fireground radio channel and communicated to dispatch include but are not limited to: 
- On-scene arrival

- Scene size up (360 degree size up complete or communicate portion of size up complete)

- Making entry

- Water supply established

- Hoseline charged

- Water on fire

- Fire knocked down

- Ventilation in process

- Ventilation complete (windows or doors opened, roof ventilation complete, etc.)

- Search complete

- Fire under control.

During this incident, many of these benchmarks were not communicated over the radio. Verbal exchanges between the interior crews and company officers took place, but this information did not reach the incident commander to help make tactical decisions in fighting the fire and to aid in accountability.

Recommendation \#9: Dispatch centers should provide timeframe benchmarks to Incident Command on a regular basis.

Discussion: Dispatchers are a critical link in the chain of survival for fire fighters operating in emergency situations, and an effective dispatch system is a key factor in fire department operations. The central dispatch center is used for receiving notification of emergencies, alerting personnel and dispatching equipment, coordinating the activities of the units engaged in emergency incidents, and providing non-emergency communications for the coordinating fire departments [IFSTA 1998; NFPA 1997, 2013c]. The dispatch system must be able in advance to identify the type and number of units due to respond to the type of incident based on risk criteria and unit capabilities [NFPA 2014].

Central Dispatch should be staffed with operators who are trained to understand fire department operations, terminology, and the role the operator plays in fire fighter survival. Central Dispatch could then also monitor fireground activity and inform Command of time intervals and of possible missed transmissions, such as Maydays. Dispatchers are in a position to objectively monitor and report time intervals (e.g., every 10 minutes). Such time intervals are critical as most Mayday events occur within the first $10-15$ minutes of fire fighting operations, coincident with the expected effective available air in an SCBA cylinder used by a fire fighter doing moderate work. A central dispatch center equipped with regional mutual aid channels could serve multiple jurisdictions. This type of system would provide operational advantages in the communication system, reflect a more functional mutual aid system, and reduce overall costs of operating centers in individual jurisdictions [Sealy 2003]. Dispatch centers need to evaluate their role in fireground operations. In addition to providing timeframe benchmark reports to the incident commander, Dispatch can play an important role in prompting 


\section{Volunteer Fire Fighter Dies After Running Out of Air and Becoming Disoriented in Retail Store in Strip Mall Fire-North Carolina}

Command to consider building evacuations, providing building evacuation tones, giving prompts on whether or not to change radio channels during a Mayday, and many other important issues that directly affect fire fighter safety and health.

In this incident, the fire department and the dispatch center did not have a procedure for broadcasting automatic time interval updates over the fireground channel. Dispatch did not provide Command with benchmark time references (i.e., 10 minutes on-scene, 20 minutes on-scene, etc.).

\section{Recommendation \#10: Fire departments should ensure that Mayday training programs are developed and implemented so that fire fighters are adequately prepared to call a Mayday.}

Discussion: The highest priority in fire fighter safety is avoiding situations that render responders unable to perform their duties effectively. The fire fighter must maintain situational awareness at all times while operating on the fireground. Fire fighters must understand that when they are faced with a life-threatening emergency, there is a very narrow window of survivability, and any delay in egress and/or transmission of a Mayday message reduces the chance for a successful rescue. Knowledge and skill training on how to prevent a Mayday situation and how to call a Mayday should begin and be mastered before a fire fighter engages in fireground activities or other immediately-dangerous-to-lifeor-health environments. Mayday training should include utilizing a standard pneumonic that is practiced regularly. One example is L-U-N-A-R (Location, Unit, Name, Assignment and Air, Resources). Calling a Mayday is not intuitive. Fire fighters must, from a very early point in their basic training, understand the circumstances under which they should call a Mayday. This can and should be accomplished through non-IDLH scenario-based training that mimics circumstances a fire fighter is expected to encounter [Clark 2005, 2008].

Beginner fire fighter training programs should include training on such topics as air management; familiarity with an SCBA, a radio, and personal protective equipment; crew integrity; reading smoke, fire dynamics, and fire behavior; entanglement hazards; building construction; and signs of pending structural collapse. Fire fighters must be able to recognize when they find themselves in a questionable position (whether immediately dangerous or not) and be trained on procedures for when and how a Mayday should be called. A fire fighter's knowledge, skill, and ability to declare a Mayday must be at the mastery level of performance. This performance level should be maintained throughout their career through training offered more frequently than annually [IAFF 2012].

Fire departments must understand that each fire fighter may have a different interpretation of what is life-threatening. The ability of a fire fighter to call a Mayday is a complicated behavior that includes the affective, cognitive, and psychomotor domains of learning and performance [Clark 2005;

Grossman and Christensen 2008]. Any delay in calling a Mayday reduces the chance of survival and increases the risk to other fire fighters trying to rescue the downed fire fighter. This incident illustrates the need for fire fighters to be given specific training on determining when a Mayday must be called.

No rules are established for determining when a Mayday must be called, and Mayday training is not included in the job performance requirements in NFPA Fire Fighter I or II standards. It is up to the 


\section{Volunteer Fire Fighter Dies After Running Out of Air and Becoming Disoriented in Retail Store in Strip Mall Fire-North Carolina}

authority having jurisdiction to train members for emergency operations [NFPA 2013a,c] and to develop rules and performance standards for a fire fighter to call a Mayday. The National Fire Academy (NFA) has an on-line course addressing the fire fighter Mayday doctrine: Q133 Firefighter Safety, Calling the Mayday, a 2-hour program covering the cognitive and affective learning domain of the fire fighter Mayday doctrine [Clark 2005]. The NFA course H0134 Calling the Mayday: Hands-on Training, an 8-hour course covering the psychomotor learning domain of the fire fighter Mayday doctrine, was handed off to state fire training academies and metro fire departments [Clark 2008]. These courses are based on the military methodology used to develop and teach ejection doctrine to fighter pilots. The NFA Mayday courses present specific Mayday parameters or rules for determining when a fire fighter must call a Mayday. The courses may help fire departments in developing and teaching Mayday procedures for fire fighters. Also, NFPA 1001 Standard for Fire Fighter

Professional Qualifications includes job performance requirements related to the fire fighter calling for assistance (such as a Mayday situation) [NFPA 2013a].

The International Association of Fire Fighters (IAFF) Fire Ground Survival program is another resource for fire departments and was developed to ensure that training for Mayday prevention and Mayday operations is consistent among all fire fighters, company officers, and chief officers [IAFF 2012].

Any Mayday communication must contain the location of the fire fighter in as much detail as possible and, at a minimum, should include the division (floor) and quadrant. It is imperative that fire fighters always know their location when in IDLH environments to effectively be able to give their location in the event of a Mayday. Once in distress, fire fighters must immediately declare a Mayday. The following example uses LUNAR (Location, Unit, Name, Assignment/Air, Resources needed) as a prompt: "Mayday, Mayday, Mayday, Division 1 Quadrant C, Engine 71, Smith, search/out of air/vomited, can't find exit." When in trouble, a fire fighter's first action must be to declare the Mayday as accurately as possible. Once the incident commander and rapid intervention team (RIT) know the fire fighter's location, the fire fighter can then try to fix the problem, such as clearing the nose cup, while the RIT is en route for rescue [USFA 2006].

A fire fighter who is breathing carbon monoxide (CO) quickly loses cognitive ability to communicate correctly and can unknowingly move away from an exit, other fire fighters, or safety before becoming unconscious. Without the accurate location of a downed fire fighter, the speed at which the RIT can find them is diminished, and the window of survivability closes quickly because of lack of oxygen and high CO concentrations in an IDLH environment [Clark 2005, 2008; USFA 2006].

In this incident, the Engine 3 Fire Fighter 2 and the Engine 3 lieutenant became separated from the hoseline while attempting to exit the fire building, became disoriented, and could not exit. The Engine 3 lieutenant did not have a radio so he could not call a Mayday. The Engine 3 Fire Fighter 2 had a radio but did not use it. It was reported that during this incident, the Engine 3 Fire Fighter 2 was operating on a hoseline in the interior of a burning structure fire for the first time. 


\section{Volunteer Fire Fighter Dies After Running Out of Air and Becoming Disoriented in Retail Store in Strip Mall Fire-North Carolina}

\section{Recommendation \#11: Fire departments should ensure that fire fighters are trained and proficient on following hoselines outside as a means for egress and self-rescue.}

Discussion: Fire fighters should always work and remain in teams whenever they are operating in a hazardous environment. Team integrity depends on team members knowing who is on their team and who is the team leader; staying within visual contact at all times (if visibility is low, teams must stay within touch or voice distance of each other); communicating needs and observations to the team leader; and rotating together for team rehab, team staging, and watching out for each other (e.g., practicing a strong buddy system). Following these basic rules helps prevent serious injury or even death by providing personnel with the added safety net of fellow team members. Teams that enter a hazardous environment together should leave together to ensure that team continuity is maintained.

Hoselines can be the last line of defense and the last chance for a lost fire fighter to find egress from a burning building. According to the USFA Special Report, Rapid Intervention Teams and How to Avoid Needing Them, the basic techniques taught during entry-level fire-fighting programs describe how to escape a zero-visibility environment using only a hoseline [USFA 2003]. However, as years elapse from the time of basic training, fire fighters may overlook this technique. Exiting a structure in zero visibility should be simple, fast, and easy for a fire fighter with a hoseline based on training and experience to build muscle-memory. A fire fighter operating on a hoseline should search along the hose until a coupling is found. Once found, the fire fighter can "read" the coupling and determine the male and female ends. The IFSTA manual Essentials of Fire Fighting teaches that the female coupling is on the nozzle side of the set and the male is on the water side of the set. In most cases, the male coupling has lugs on its shank while the female does not. Once oriented on the hose, fire fighters can follow the hoseline in the direction away from the male coupling which will take them toward the exit (see Diagram 1)[IFSTA 1998, NIOSH 2009]. A fire hose can also be marked in a number of ways that will indicate the direction to the exit, including the use of raised arrows and chevrons that provide both visual and tactile indicators. Fire departments may use a variety of techniques to train fire fighters on how to identify hoseline couplings and the direction to the exit, based on the model of hose used by the department. The key point is that this training needs to be conducted and repeated often so that fire fighters are proficient in identifying the direction to the exit in zero-visibility conditions while wearing gloves, when the hose is entangled, and with various obstructions present. This procedure should be incorporated into standard operating procedures, trained upon, and enforced on the fireground. 
Volunteer Fire Fighter Dies After Running Out of Air and Becoming Disoriented in Retail Store in Strip Mall Fire-North Carolina

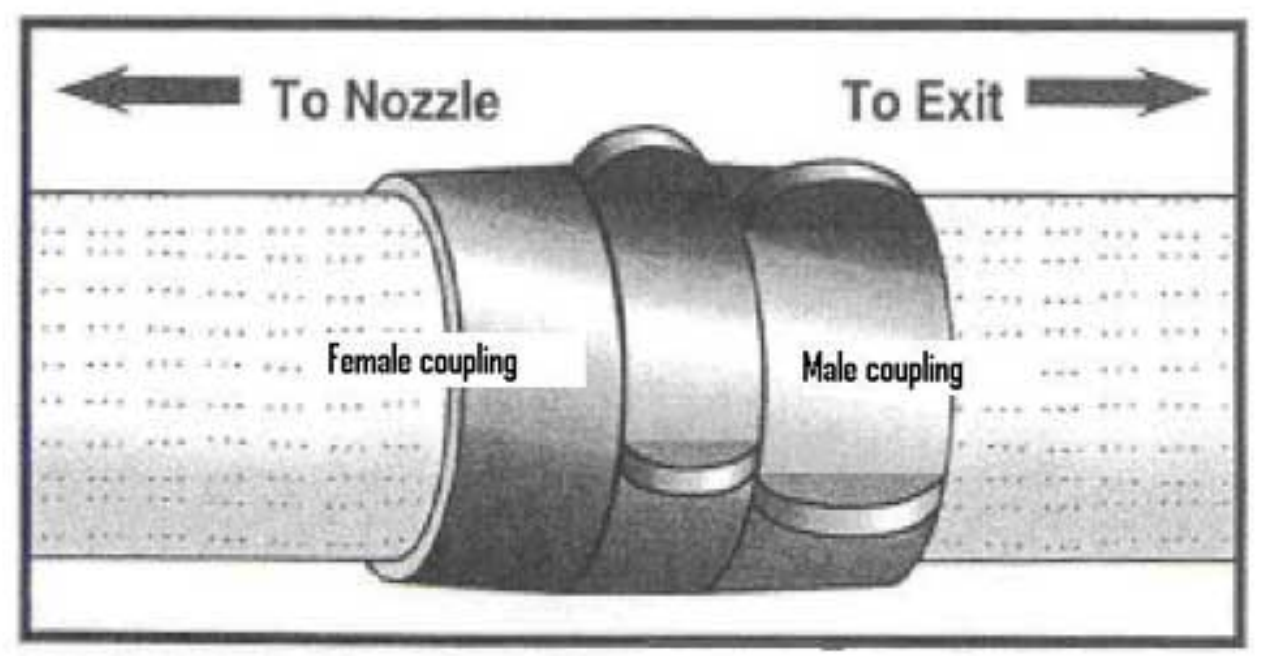

Diagram1. Hose couplings will indicate the direction toward the exit. (Adapted from IFSTA Essentials of Fire Fighting, $4^{\text {th }}$ Edition.)

In this incident, Engine 3 Fire Fighter 2 ran low on air and told his crew members that he needed to get out. He began following the hoseline but soon lost contact with the hoseline due to the arrangement of the display racks in the store. The other crew members attempted to calm him down. The Engine 3 lieutenant also ran low on air and stated that he would take the fire fighter outside. The Engine 3 lieutenant and fire fighter again began to follow the hoseline outside. The lieutenant turned around to check on the fire fighter and noticed that he was standing up and soon disappeared into the near-zero visibility conditions within the store. The lieutenant soon lost contact with the hoseline. Both Fire Fighter 2 (the victim) and lieutenant ran completely out of air. The Engine 16 crew heard the lieutenant yelling for help, was able to locate him, and assist him outside. The Engine 3 Fire Fighter 2 was located about 2 minutes later. Fire Fighter 2 was immediately transported to a hospital but did not survive his injuries. The lieutenant was treated and released.

\section{Recommendation \#12: Fire departments should ensure that fire fighters are trained in fireground survival procedures.}

Discussion: As part of emergency procedures training, fire fighters need to understand that their personal protective equipment and SCBA (PPE) do not provide unlimited protection. PPE that is not properly donned, worn, or activated may provide reduced protection or no protection at all. In such cases, delay in egress to transmit a Mayday message may be fatal. However, the Mayday message should be transmitted as soon as the crew is in a defensible position. The International Association of Fire Fighters (IAFF) and the International Association of Fire Chiefs (IAFC) have developed the IAFF 


\section{Volunteer Fire Fighter Dies After Running Out of Air and Becoming Disoriented in Retail Store in Strip Mall Fire-North Carolina}

Fire Ground Survival program to ensure that training for Mayday prevention and Mayday operations are consistent between all fire fighters, company officers, and chief officers [IAFF 2012]. Fire fighters must act promptly when they become lost, disoriented, injured, low on air, or trapped [Angulo et al. 2004; Carter el al. 2000; DiBernardo 2003; Hoffman 2002; Miles and Tobin 2004; Sendelbach 2004].

After quickly assessing the tenability of their location, the fire fighter must transmit a Mayday while they still have the capability and sufficient air, noting their location if possible. As noted above, fire fighters may need to move away from untenable fire conditions before calling the Mayday. The next step is to manually activate their personal alert safety system (PASS) device. To conserve air while waiting to be rescued, fire fighters should try to stay calm, be focused on their situation and avoid unnecessary physical activity. They should survey their surroundings to get their bearings and determine potential escape routes such as windows, doors, hallways, and changes in flooring surfaces, and stay in radio contact with the incident commander and other rescuers. Additionally, fire fighters can attract attention by maximizing the sound of their PASS device (e.g., by pointing it in an open direction), pointing their flashlight toward the ceiling or moving it around, and using a tool to make tapping noises on the floor or wall.

A crew member who initiates a Mayday call for another person should quickly try to communicate with the missing member via radio and, if unsuccessful, initiate another Mayday providing relevant information on the missing fire fighter's last known location. Training should include situations dealing with "uncontrolled” SCBA emergencies, egress through small openings, emergency window egress, building collapse, and other situations that could be encountered during a Mayday situation.

Additional emphasis must be placed on appropriate procedures for tactical withdrawal under worsening fire conditions and/or pending building collapse [Dodson 2005]. The use of an operational retreat is designed to quickly remove fire fighters from operations in an unsafe or potentially unsafe environment. The incident commander shall initiate an operational retreat whenever the operational area is deemed unsafe for emergency personnel. All personnel operating in the unsafe area shall evacuate as the operational retreat procedures are initiated. Operational retreat shall begin with radio traffic announcing “EMERGENCY TRAFFIC” with directions for all emergency personnel to evacuate the operational area. An emergency egress signal shall be sounded. An example of an emergency egress signal would be 10 seconds of short air horn blasts, followed by 10 seconds of silence, with the sequence repeated three times.

Upon hearing the operational retreat signal, all fire fighters should immediately withdraw from any operations they are performing and leave the operational area. All company officers should immediately perform a personnel accountability report (PAR) of all personnel they are responsible for and report the results to the incident commander.

In addition, fire fighters need to understand the psychological and physiological effects of the extreme level of stress encountered when they become lost, disoriented, injured, run low on air, or trapped during rapid fire progress. Most fire training curriculums do not include discussion of the 


\section{Volunteer Fire Fighter Dies After Running Out of Air and Becoming Disoriented in Retail Store in Strip Mall Fire-North Carolina}

psychological and physiological effects of extreme stress such as encountered in an imminently life threatening situation, nor do they address key survival skills necessary for effective response.

Understanding the psychology and physiology involved is an essential step in developing appropriate responses to life-threatening situations. Reaction to the extreme stress of a life-threatening situation (such as being trapped by extreme fire behavior or building collapse) can result in sensory distortions and decreased cognitive processing capability [Grossman and Christensen 2008].

As noted, training is frequently limited to breathing apparatus emergencies, egress through small openings, emergency window egress, etc. Additional emphasis must be placed on appropriate procedures for tactical withdrawal under worsening fire conditions and structural collapse situations. Modern self-contained breathing apparatus (SCBA) contain a feature known as the "emergency escape breathing support system" or EBSS. This system allows the "donor" fire fighter to transfer some of the air in their SCBA cylinder to a "receiver" fire fighter who may be low on air, injured, trapped, or otherwise in distress. The decision to use the EBSS is a conscious one made under extremely harsh and hazardous conditions. If the fire department supports the use of EBSS, all fire fighters need to be thoroughly trained in its effective use.

In this incident, the Engine 3 Fire Fighter 2 did not transmit a Mayday message. A Mayday was not transmitted until after the Engine 3 lieutenant came outside and the missing Engine 3 Fire Fighter 2 was discovered by the Engine 16 and Engine 20 crews. The Engine 3 lieutenant did not have his radio with him while he was inside the structure. The Mayday was transmitted by the Engine 20 captain when the missing fire fighter was located.

Recommendation \#13: Fire departments should ensure that appropriate staffing levels are available on-scene to accomplish fireground tasks and be available for unexpected emergencies including the establishment of a dedicated rapid intervention crew (RIC) or team (RIT).

Discussion: Adequate resources are needed at incident scenes to ensure rapid incident stabilization and to promote fire fighter safety. A department should pre-plan the tasks that may be performed at any structural fire prior to response and develop response packages to address the tasks. From determining the required fire flow, to stretching hoselines, forcing entry, search, rescue, extinguishment and much more, fire departments should consider what the staffing needs are in order to simultaneously perform these tasks. The planning for the first-alarm assignment needs to include sufficient additional unassigned fire fighters to be on-scene, staged and ready to assist with fireground operations in the event of an emergency or to allow for on-scene fire fighter rehabilitation. Incident commanders should recognize the limits of available resources to complete fireground tasks and adjust their desired action plan to coincide with resources on hand.

In addition, a study released by the National Institute for Standards and Technology (NIST), Report on Residential Fireground Field Experiments, concluded that a three-person crew started and completed a primary search and rescue $25 \%$ faster than a two-person crew and that a four or five-person crew started and completed a primary search and rescue 6\% faster than a three-person crew [NIST 2010]. 


\section{Volunteer Fire Fighter Dies After Running Out of Air and Becoming Disoriented in Retail Store in Strip Mall Fire-North Carolina}

In order to ensure compliance with 29 CFR 1910.134, Respiratory Protection, [OSHA 1998] fire departments must maintain a rapid intervention crew or company when members are operating in an immediately dangerous to life and health (IDLH) or potentially IDLH atmosphere.

The RIC function should be incorporated into the department's incident management system and the personnel accountability system [NFPA 2014]. Critical fireground operations and staffing needs should be continuously evaluated in regards to fire fighter safety. Resource assignments should be made with the goal of having the RIC function in place at all times. When the incident commander needs additional resources, the consideration of deploying the rapid intervention team for an operational assignment without additional resources on-scene to function as a RIC should be carefully assessed [NFPA 2014].

The following restrictions regarding the use of a RIC should be considered by the incident commander during fireground operations:

- The RIC should not be used for fire-fighting operations.

- The RIC is dedicated to assist, and if necessary, rescue members who become trapped, distressed, or involved in other serious life-threatening situations.

- The RIC should not be used to provide relief for operating companies until the fire/incident has been declared “Under Control” by Command.

- If assigned by a superior officer to other than RIC duties, the RIC unit officer should remind such officer of RIC designation [Toledo Fire \& Rescue Department 2012; TSFRS 2014].

When the incident commander orders the RIC to work, the incident commander should immediately assign another on-scene company to stand by as the RIC. At a minimum, the incident commander should request an additional alarm and designate a company or companies to function as RIC. The remainder of the companies should report to staging. If no units are available, the incident commander should assign at least two members to act as a rapid intervention team while awaiting a special-called RIC to arrive. An engine company may be designated as the RIC pending arrival of an additional ladder company or rescue company. This ensures compliance with OSHA's “Two In/Two Out” rule under 29 CFR 1910.134, Respiratory Protection [OSHA 1998].

Upon deploying a RIC, the incident commander must expand the Incident Action Plan or IAP to reflect a high-priority rescue effort, focusing resources on the simultaneous tasks of controlling the fire and rescuing the endangered fire fighter(s). Such changes in the IAP need to be announced over the radio so that everyone on the incident scene and in the Dispatch Center, understands what is happening. Consideration should be given to expanding the Incident Organizational Structure to include a Rescue Branch (focused on RIC activities) and a Suppression Branch (focused on fire fighting). In this way, Command assigns a Branch Director (a Chief Officer) to each branch and addresses both functions requiring immediate attention. This action also reduces the likelihood of overwhelming the incident commander with "task saturation," a condition in which auditory and sensory inputs overload an individual's ability to maintain situational awareness, leading to a failure at the command level. 


\section{Volunteer Fire Fighter Dies After Running Out of Air and Becoming Disoriented in Retail Store in Strip Mall Fire-North Carolina}

Many fire departments have a defined response plan for the dispatch of an additional company (engine, truck, squad, or rescue) to respond to an incident and stand by as the rapid intervention team. Based upon the complexity, magnitude, configuration of the structure, or geographical layout of the incident, the incident commander may deploy additional RIC by location or function [NFPA 2014].

Upon arrival or upon appointment, the RIC officer should confer with the incident commander. The RIC officer should establish an area to stage the RIC and the necessary RIC equipment. The RIC equipment should include:

- A tool staging tarp

- Rescue SCBA (RIC Pack)

- Forcible entry tools such as a Halligan bar or other pry tool

- Stokes basket

- 150-foot rope for search and rescue

- Wire cutters

- Rebar cutter

- Saws

- Thermal imager

- Emergency strobe lights

- Life-saving rope/life belt

- Elevator keys for buildings with elevators [FDNY 2011; LAFD 2001; TSFRS 2014].

It is important to stage all necessary RIC equipment in an expedient manner (see Photo 8). The RIC officer (equipped with a thermal imager), accompanied by one member of the RIC, should perform an incident scene survey while the remaining RIC members assemble the RIC equipment. If the size of the structure negates a 360-degree survey of the building, this fact should be relayed to the incident commander as soon as possible. This should be a benchmark for Command to designate another RIC in order to effectively cover all sides of the building.

During this survey, the RIC officer and members should look for ways in and out of the structure, including window configuration, fire escapes, and construction features. The RIC officer should note the feasibility for placement of ground ladders for rescue or escape purposes. The RIC officer should be responsible for setting up and securing a suitable secondary egress for interior crews. This may include laddering multiple sides of the structure. Once the RIC has determined the need for an egress ladder, the window glass should be removed. This should only be done after conferring with Command that the removal of the window will not affect fire fighting operations. Once approved by Command, the egress ladder should be placed at the window. The location of the egress ladder(s) shall be announced over the radio by the RIC officer [Toledo Fire \& Rescue Department 2012].

After the above tasks are completed, the RIC officer should inform Command that a 360-degree survey is complete and the RIC is ready to intervene, if necessary. Once the incident scene survey has been 


\section{Volunteer Fire Fighter Dies After Running Out of Air and Becoming Disoriented in Retail Store in Strip Mall Fire-North Carolina}

completed and the RIC equipment is in place, the entire RIC should be located in an area immediately accessible to the building in order for rapid deployment plus maintaining radio contact with Command. The RIC officer should brief all members of the RIC as to the results of his/her incident scene survey. The RIC should operate as one unit. Additional crews may be added to or in support of the team as necessary. When more than one company is added as part of the rapid intervention team, a rescue group should be formed with a rescue group supervisor [Toledo Fire \& Rescue Department 2012].

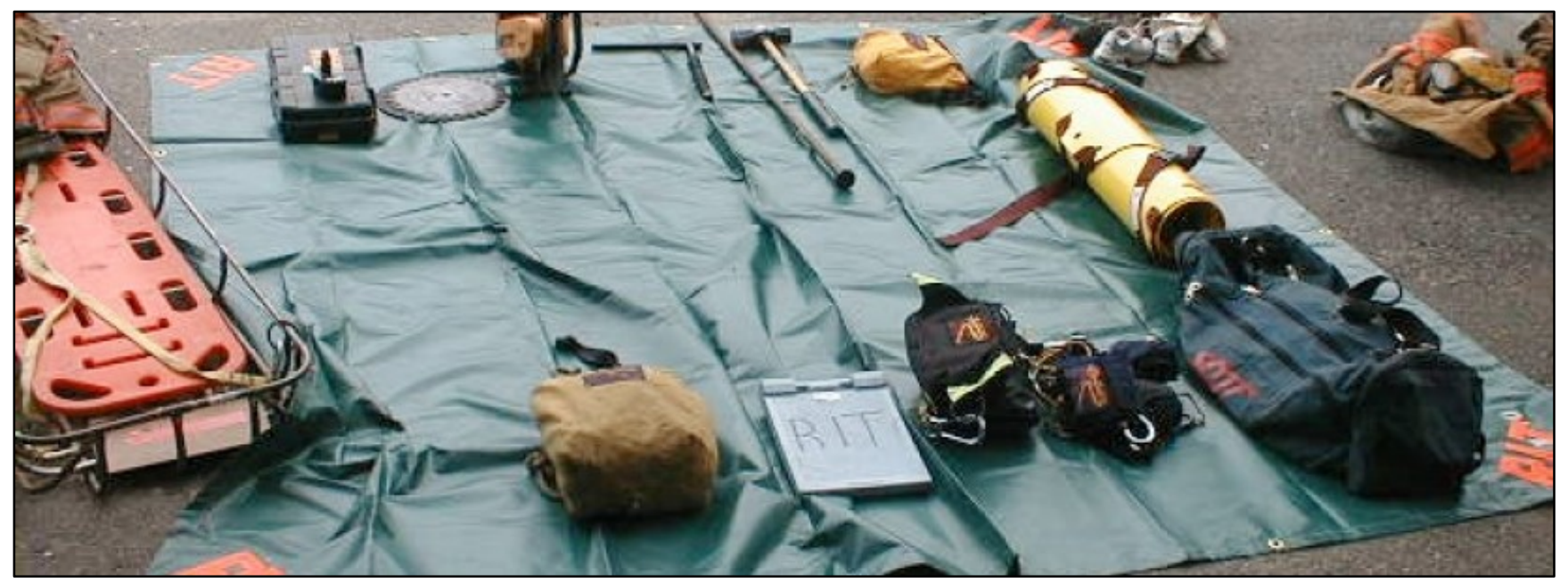

Photo 8. This is an example of the equipment needed for rapid intervention crew (RIC) operations. One of the most important pieces of equipment is the strobe light, which can be used to identify/mark an exit in a building in the event a rapid egress is needed by a fire

fighter or fire fighters.

(Photo courtesy of the Google Bing.com Free Photo Search.)

The RIC officer and RIC members will coordinate with Command to formulate rescue plan contingencies and continue to monitor the radio and fireground conditions. RIC protection is not a passive assignment. This is a process of ongoing information gathering and diligent scene monitoring until the unit is released by the incident commander. The RIC function is a critical component for fire fighter safety.

In this incident, a dedicated rapid interview crew was never established.

Recommendation \#14: Fire departments should provide all fire fighters with radios and train them on their proper use.

Discussion: In September 2003, NIOSH released the document, Current Status, Knowledge Gaps, and Research Needs Pertaining to Firefighter Radio Communication Systems [TriData 2003]. Page 13 states: "It is critical for firefighters to communicate with one another within a structure and with units 


\section{Volunteer Fire Fighter Dies After Running Out of Air and Becoming Disoriented in Retail Store in Strip Mall Fire-North Carolina}

operating outside the structure, regardless of the building construction.” The best way this can be done when crews are separated or in trouble is through the use of a personal portable radio.

National Fire Protection Association (NFPA) 1561, Standard on Emergency Services Incident Management System and Command Safety, Section 6.3 Emergency Traffic, states in section 6.3.1: “To enable responders to be notified of an emergency condition or situation when they are assigned to an area designated as immediately dangerous to life or health (IDLH), at least one responder on each crew or company shall be equipped with a portable radio and each responder on the crew or company shall be equipped with either a portable radio or another means of electronic communication” [NFPA 2014]. The joint U.S. Fire administration (USFA) and International Association of Fire Fighters (IAFF) report, Voice Radio Communications Guide for the Fire Service [USFA/IAFF 2008, 2016], provides an overview of radio communication issues involving the fire service. Effective fireground radio communication is an important tool to ensure fireground command and control as well as helping to enhance fire fighter safety and health. Every fire fighter on the fireground should be provided with their own radio in case they become lost or separated from their crew. It is every fire fighter's and company officer's responsibility to ensure radios are properly used. Ensuring appropriate radio use involves both taking personal responsibility (to have your radio, having it on, and on the correct channel) and a crew-based responsibility to ensure that the other members of your crew are doing so as well. Radios should be designed and positioned to allow the fire fighter to monitor and transmit a clear message. These radios should be well maintained and inspected by qualified personnel on a regular basis.

The fire department involved in this incident typically issues a radio to every fire fighter. In this incident, the Engine 3 lieutenant dropped his radio while donning his personal protective clothing and equipment inside Engine 3 while en route to the fire. The lieutenant was not able to locate his radio in a timely manner and entered the structure without his radio. During interviews, other fire fighters reported to NIOSH investigators that they were working inside the structure and did not have a portable radio.

Both the International Association of Fire Chiefs (IAFC) [IAFC 2009] and the International Association of Fire Fighters (IAFF) [USFA/IAFF 2008] recommend that all fire fighters be assigned a radio. In 1999, the U.S. Fire Administration technical report Improving Firefighter Communications identified a number of radio communication issues, including the need for all fire fighters to have portable radios. The report stated "Ideally, every firefighter working in a hostile environment should have a portable radio with emergency distress feature [USFA 1999].” The IAFF Fireground Survival Program contains training on radio communication procedures in emergency operations including how to call a Mayday [IAFF 2012].

Issuing a radio to every fire fighter is not enough. Training must accompany any effort to improve fireground communication. First and foremost, the fireground radio frequency can become congested, especially during the early stages when the incident is not yet under control. As such, radio discipline is important and messages should be limited to those of an important tactical nature (Conditions- 


\section{Volunteer Fire Fighter Dies After Running Out of Air and Becoming Disoriented in Retail Store in Strip Mall Fire-North Carolina}

Actions-Needs or CAN report), accountability (PAR) report, and fireground emergencies (Mayday). Second, training must also encompass circumstances when an incident commander opts to change radio frequencies. This is a potentially dangerous action and should only be undertaken in the most extreme circumstances given the possibility of "losing" personnel in the movement from one channel to another. After switching frequencies, command should conduct a PAR to confirm that the appropriate units are operating on the correct channel.

\section{Recommendation \#15: Standard setting organizations, enforcement agencies, and authorities having jurisdiction should consider developing, implementing, and enforcing national fire fighter and fire officer training standards and requirements.}

Discussion: Most large and metropolitan fire departments have dedicated resources that establish training requirements and curriculum meeting the needs of the location and population served. Smaller departments (paid, combination, or volunteer) may have limited resources to devote to training purposes. Most states delegate the actual training requirements to the fire chief or the authority having jurisdiction over the fire department. The result is that training requirements, and thus the training itself, varies widely from location to location across the United States.

Standard setting organizations, states, and authorities having jurisdiction should consider developing national standards so that fire fighters across the United States are trained to the same minimum levels. Additionally, combination and volunteer fire departments should ensure that all members, regardless of pay status, are trained to identical standards. Departments should not rely on other agencies to ensure training is provided. Although company-level (hands-on) training is critical, it should not replace formal training and certification. The fire does not differentiate between well-trained, experienced fire fighters and those less experienced and trained. There is a dramatic difference between a 20-year veteran fire fighter in an urban setting and a recently graduated rookie fire fighter from any department, regardless of size. At its core, probationary fire fighter training programs are designed to produce fire fighters who are prepared to function as a member of a team, not independently. Such fire fighters rely on their company officers to ensure their safety while operating in an IDLH environment.

In this incident, the volunteer fire department involved had numerous members who also worked fulltime for the adjoining career metropolitan department where training standards were extensive. This created a circumstance under which some members of the department received formal training from the career department that was significantly different from that received by volunteer members. The unintended result may have led to unrealistic (and even unconscious) expectations being placed on newer, less experienced members. The Engine 3 Fire Fighter 2 encountered conditions that he may not have been sufficiently trained and experienced to deal with. It was reported that this was the first working fire that the Engine 3, Fire Fighter 2 had made entry as part of a hoseline crew and worked the nozzle. 


\section{Volunteer Fire Fighter Dies After Running Out of Air and Becoming Disoriented in Retail Store in Strip Mall Fire-North Carolina}

\section{Recommendation \#16: Fire departments should utilize a functional personnel accountability system, requiring a check-in and check-out procedure with the designated accountability officer or incident commander.}

Discussion: Although there is no clear evidence that fireground accountability was a contributing factor in this incident, this recommendation is provided as a reminder of recommended best practices for the fire service. Fire departments should review existing personnel accountability procedures to ensure that they are functional and effective. If no personnel accountability procedures exist, the fire department should develop, implement, and enforce standard operating procedures that ensure a personnel accountability system is utilized at all emergency operations. The National Fire Protection Association (NFPA) 1561 Standard on Emergency Services Incident Management System (2014 edition), Section 4.5.1 states that the emergency services organization shall develop and routinely use a system to maintain accountability for all resources assigned to the incident with special emphasis on the accountability of personnel. Section 4.5 .3 states that the system shall include a specific means to identify and keep track of responders entering and leaving hazardous areas, especially where special protective equipment is required. Section 4.5.10 states that responders who arrive at an incident in or on marked apparatus shall be identified by a system that provides an accurate accounting of the responders on each apparatus [NFPA 2014]. NFPA 1500, Standard on Fire Department Occupational Safety and Health Program, Section 8.4 identifies requirements for personnel accountability during emergency operations. Section 8.4.1 states that the fire department shall establish written standard operating procedures for a personnel accountability system that is in accordance with NFPA 1561, [NFPA 2013c, 2014]. Section 8.4.4 of NFPA 1500 states that the incident commander shall maintain an awareness of the location and function of all companies or crews at the scene of the incident.

Personnel accountability systems can range in complexity from simple identification tags to complex electronic tracking systems. A variety of different personnel accountability systems have been used at emergency operations across the country. At emergency response incidents involving volunteer and combination fire departments, all emergency responders who respond in their privately-ownedvehicles should be required to immediately report to the incident command post and check in face-toface with Command or the designated accountability officer prior to engaging in incident activities.

The fire department involved in this incident had written standard operating procedures defining a personnel accountability system intended to meet the requirements of NFPA 1500 and NFPA 1561. The written procedures specified that the incident commander shall be responsible for overall personnel accountability for the incident and that the incident commander shall maintain an awareness of the location and function of all companies or units at the scene of the incident. The procedures also stated that the incident commander shall provide the use of additional accountability officers based on the size, complexity, or needs of the incident.

During this incident, the first-due fire department was dispatched and upon arrival, confirmed a working fire. The Department 7 fire chief (incident commander) requested a full alarm assignment from the mutual aid career department. A battalion chief from the mutual aid department arrived on 


\section{Volunteer Fire Fighter Dies After Running Out of Air and Becoming Disoriented in Retail Store in Strip Mall Fire-North Carolina}

scene and assisted Command with accountability. A number of volunteer fire fighters responded to the incident via their privately-owned-vehicles and became integrated into the emergency response.

\section{References}

Angulo RA, Clark BA, Auch S [2004]. You called Mayday! Now what? Fire Engineering 157(9):9395.

Brunacini AV [1985]. Fire command. Quincy, MA: National Fire Protection Association.

Brunacini AV [2002]. Fire command. Quincy, MA: National Fire Protection Association.

Brunacini AV [2011]. Critical fireground factors. Fire Engineering, June: 42-43.

Carter W, Childress D, Coleman R, et al. [2000]. Firefighter's Handbook: Essentials of firefighting and emergency response. Albany, NY: Delmar Thompson Learning.

Clark BA [2005]. 500 Maydays called in rookie school. Firehouse.com.

Clark BA [2008]. Leadership on the line: Firefighter Mayday doctrine where are we now? Firehouse.com.

DiBernardo JP [2003]. A missing firefighter: Give the Mayday. Firehouse, Nov: 68-70.

Dodson D [2005]. The art of first-due. Fire Engineering, March: 135-141.

Dunn V [1988]. Collapse of burning buildings: A guide to fireground safety. Saddle Brook, NJ: Fire Engineering Books and Videos.

Dunn V [2007]. Strategy of firefighting. Saddlebrook NJ: Penn Well Publishing Co.

FDNY [2011]. Fire fighter assist and search team. In: Managing members in distress. New York: Fire Department of New York.

Gagliano M, Phillips C, Jose P, Bernocco S [2008]. Air management for the fire service. Tulsa, OK:

Penn Well Corporation, Fire Engineering.

Grorud LJ [2009]. Written comment to NIOSH Docket \#141, March 3.

Grossman D, Christensen L [2008]. On combat: The psychology and physiology of deadly conflict in war and peace. 3rd ed. Millstadt, IL: Warrior Science Publications.

Hoffman JJ [2002]. MAYDAY-MAYDAY-MAYDAY. Fire Department Safety Officers Association health and safety for fire and emergency service personnel, 13(4):8.

IAFC [2009]. Position statement: Assignment of portable radios/two-way communications devices to every firefighter on the fireground. Fairfax, VA: International Association of Fire Chiefs.

IAFC [2012]. Rules of engagement for structural firefighting. Fairfax VA: International Association of Fire Chiefs, Safety, Health and Survival Section.

IAFF [2012]. IAFF Fire Ground Survival Program. Washington, DC: International Association of Fire Fighters. 


\section{Volunteer Fire Fighter Dies After Running Out of Air and Becoming Disoriented in Retail Store in Strip Mall Fire-North Carolina}

IFSTA [1998]. Essentials of fire fighting. 4th ed. Stillwater, OK: Oklahoma State University, International Fire Service Training Association.

LAFD [2001]. Rapid intervention company, fireground safety and incident accountability. Los Angeles, CA: Los Angeles Fire Department.

Miles J, Tobin J [2004]. Training notebook: Mayday and urgent messages. Fire Engineering 157(4):22.

NFA [2004]. Incident safety officer (ISO). Emmitsburg, MD: Federal Emergency Management Agency, United States Fire Administration, National Fire Academy.

NFPA [1997]. Fire protection handbook. 18th ed. Quincy, MA: National Fire Protection Association.

NFPA [2008]. Fire Protection Handbook. 20th ed. Quincy, MA: National Fire Protection Association.

NFPA [2012]. NFPA 1403 Standard on live fire training evolutions. Quincy, MA: National Fire Protection Association.

NFPA [2013a]. NFPA 1001 Standard for fire fighter professional qualifications. Quincy, MA: National Fire Protection Association.

NFPA [2013b]. NFPA 1404 Standard for fire service respiratory protection training. Quincy, MA: National Fire Protection Association.

NFPA [2013c]. NFPA 1500 Standard on fire department occupational safety and health program. Quincy, MA: National Fire Protection Association.

NFPA [2014]. NFPA 1561: Standard on emergency services incident management system and command safety. Quincy, MA: National Fire Protection Association.

NFPA [2015]. NFPA 1620 Standard for pre-incident planning. Quincy, MA: National Fire Protection Association.

NIOSH [1999]. NIOSH Alert: Request for assistance in preventing injuries and deaths of fire fighters due to structural collapse. Cincinnati, OH: U.S. Department of Health and Human Services, Centers for Disease Control and Prevention, National Institute for Occupational Safety and Health, DHHS (NIOSH) Publication No. 99-146.

NIOSH [2009]. A career captain and a part-time fire fighter die in a residential floor collapse-Ohio. Morgantown, WV: U.S. Department of Health and Human Services, Centers for Disease Control and Prevention, National Institute for Occupational Safety and Health, FACE Report F2008-09,

NIOSH [2010]. Preventing deaths and injuries of fire fighters using risk management principles at structure fires. Cincinnati, OH: U.S. Department of Health and Human Services, Centers for Disease Control and Prevention, National Institute for Occupational Safety and Health, DHHS (NIOSH) Publication No.2010-153.

NIST [2010]. Report on residential fireground field experiments. Gaithersburg, MD: National Institute of Standards and Technology, NIST Technical Note 1661. 


\section{Volunteer Fire Fighter Dies After Running Out of Air and Becoming Disoriented in Retail Store in Strip Mall Fire-North Carolina}

OSHA [1998]. 29 CFR Parts 1910 and 1926 Respiratory Protection; Final Rule. Federal Register Notice 1218-AA05. Vol. 63, No. 5. January 8, 1998. U.S. Department of Labor, Occupational Safety and Health Administration. Washington DC.

PFD [2009]. Written comment to NIOSH Docket \#141. Phoenix Fire Department, Phoenix, AZ, March 9.

Sealy CL [2003]. Multi-company training: Part 1. Firehouse, February.

Sendelbach TE [2003]. Managing the fireground Mayday: The critical link to firefighter survival.

Firehouse.com, May 8. http://www.firehouse.com/article/10541890/managing-the-fireground-mayday.

Date accessed: October 2017.

Toledo Fire \& Rescue Department [2012]. Rapid intervention team (RIT) standard operating procedure C82. Toledo, OH: Toledo Fire \& Rescue Department.

TriData Corporation [2003]. Current status, knowledge gaps, and research needs pertaining to fire fighter radio communication systems. Report prepared for NIOSH. Arlington, VA: TriData Corporation.

TSFRS [2014]. Rapid intervention team, interim procedure 2014-003. West Lawn, PA: Township of Spring Fire \& Rescue.

USFA [1999]. Special report: improving firefighter communications. Emmitsburg, MD: U.S. Department of Homeland Security, U.S. Fire Administration, Technical Report Series: USFA-TR-099, January.

USFA [2003]. Rapid intervention teams and how to avoid needing them. Emmitsburg, MD: U.S. Department of Homeland Security, U.S. Fire Administration, USFA-TR-123, March.

USFA [2006]. Mayday CD Q133 firefighter safety: calling the Mayday and H134 calling the Mayday: hands on training. Emmitsburg, MD: U.S. Department of Homeland Security, U.S. Fire Administration, National Fire Academy.

USFA/IAFF [2008]. Voice radio communications guide for the fire service. Emmitsburg, MD: U.S Department of Homeland Security, U.S. Fire Administration. Washington, DC: International Association of Fire Fighters.

USFA/IAFF [2016]. Voice radio communications guide for the fire service. Emmitsburg, MD: U.S. Department of Homeland Security, U.S. Fire Administration. Washington, DC: International Association of Fire Fighters.

Weather Underground [2016]. Historical weather data for April 30, North Carolina. Atlanta, GA: The Weather Chanel Interactive, Inc. 


\section{Volunteer Fire Fighter Dies After Running Out of Air and Becoming Disoriented in Retail Store in Strip Mall Fire-North Carolina}

\section{Investigator Information}

This incident was investigated by Timothy R. Merinar, Safety Engineer, Matt E. Bowyer, General Engineer, and Murrey Loflin, Investigator, with the Fire Fighter Fatality Investigation and Prevention Program, Surveillance and Field Investigations Branch, Division of Safety Research, NIOSH located in Morgantown, West Virginia. An expert technical review was provided by Assistant Chief Matthew Tobia, Loudoun County Virginia Combined Fire Rescue System. A technical review was also provided by the National Fire Protection Association, Public Fire Protection Division.

\section{Additional Information}

\section{IAFC Rules of Engagement for Firefighter Survival}

The international Association of Fire Chiefs (IAFC) is committed to reducing fire fighter fatalities and injuries. As part of that effort, the nearly 1,000-member IAFC Safety, Health and Survival Section has developed the DRAFT Rules of Engagement for Structural Firefighting to provide guidance to individual fire fighters and incident commanders regarding risk and safety issues when operating on the fireground. The intent is to provide a set of "modern procedures" for structural firefighting to be made available by the IAFC to fire departments as a guide for their own standard operating procedure development process

\section{IAFF Fire Ground Survival Program}

The purpose of the International Association of Fire Fighters (IAFF) Fire Ground Survival Program is to ensure that training for Mayday prevention and Mayday operations are consistent between all fire fighters, company officers, and chief officers. Fire fighters must be trained to perform potentially lifesaving actions if they become lost, disoriented, injured, low on air, or trapped. Funded by the IAFF and assisted by a grant from the U.S. Department of Homeland Security through the Assistance to Firefighters (FIRE Act) grant program, this comprehensive fire ground survival training program applies the lessons learned from fire fighter fatality investigations conducted by the National Institute for Occupational Safety and Health (NIOSH) and has been developed by a committee of subject matter experts from the IAFF, the International Association of Fire Chiefs (IAFC), and NIOSH.

\section{National Institute for Standards and Technology (NIST) - Fire on the Web}

Fire on the Web is a collection of resources from the Building and Fire Research Laboratory's Fire Research Division at NIST. These web pages provide links to fire-related software, experimental fire data, and mpeg/quick time movies of fire tests, which can be downloaded and/or viewed with a web browser.

\section{Underwriters Laboratories (UL) Firefighter Safety Research Institute}

An online course offered by the UL Firefighter Safety Research Institute (FSRI) highlights the tactical application of nearly two decades of research at the National Institute of Standards and Technology (NIST) and UL on how best to fight modern fires. In 2012, the New York City Fire Department (FDNY), NIST, and UL FSRI set fire to abandoned townhouses on Governors Island, New York, in a 


\title{
Volunteer Fire Fighter Dies After Running Out of Air and Becoming Disoriented in Retail Store in Strip Mall Fire-North Carolina
}

series of experiments to examine tactics for controlling fires and rescuing occupants inside burning homes.

\section{Modern Fire Behavior}

This website is meant to serve as a clearinghouse of news and training information related to Modern Fire Behavior and Modern Building Construction Research, Tactics, and Practices along with actual street experiences. ModernFireBehavior.com is a joint effort between www.FirefighterCloseCalls.com and the Underwriters Laboratories Fire Safety Research Institute.

\section{National Volunteer Fire Council}

The National Volunteer Fire Council (NVFC) is the leading nonprofit membership association representing the interests of the volunteer fire, emergency medical, and rescue services. The NVFC serves as the voice of the volunteer in the national arena and provides invaluable tools, resources, programs, and advocacy for first responders across the nation.

In 2008, the National Volunteer Fire Council (NVFC) adopted a policy position that all volunteer fire departments should establish a goal to train all personnel to a level consistent with the mission of the fire department, based on the job performance requirements outlined in NFPA 1001 Standard for Fire Fighter Professional Qualifications. The NVFC is committed to ensuring that volunteer fire fighters have an appropriate level of training to safely and effectively carry out the functions of the department(s) to which they belong. This issue actually encompasses the entire fire service and not just the volunteer ranks, as expressed the NVFC White Paper on Volunteer Fire Firefighter Training released in 2010:

\begin{abstract}
"The roles and responsibilities of the fire service have evolved over the years. As the breadth and scope of what it means to be a firefighter has expanded, to varying degrees depending on the jurisdiction, the necessity for training within the fire service has grown. Unfortunately, a large number of volunteer fire departments are still operating with personnel who are not trained to a level consistent with national consensus standards for basic firefighter preparedness. This can lead to ineffective and unsafe responses that put lives and property at risk. As the need for proper training has become more urgent, many volunteer fire departments are finding it increasingly difficult to attract new members. The average age of volunteer firefighters has risen steadily over the past two decades, as many young people move out of rural areas and the ones who stay find themselves with less free time to devote to training.”
\end{abstract}

\section{Voice Radio Communications Guide for the Fire Service}

The U.S. Fire Administration (USFA) and the International Association of Fire Fighters (IAFF) worked under a cooperative agreement to develop the Voice Radio Communications Guide for the Fire Service as a document to help identify the unique communication needs required by the fire service. This document covers basic radio communication technology, radios and radio systems, portable radio 


\section{Volunteer Fire Fighter Dies After Running Out of Air and Becoming Disoriented in Retail Store in Strip Mall Fire-North Carolina}

selection and use, trunked radio systems, system design and implementation, interoperability, and other fire service radio communication issues.

\section{Current Status, Knowledge Gaps, and Research Needs Pertaining to Firefighter Radio Communication Systems}

The National Institute for Occupational Safety and Health (NIOSH) commissioned a study to identify and address specific deficiencies in fire fighter radio communications and to identify technologies that may address these deficiencies. Specifically to be addressed were current and emerging technologies that improve, or hold promise to improve, fire fighter radio communications and provide fire fighter location in structures. This report was prepared under contract with NIOSH. It should not be considered a statement of NIOSH policy or of any agency or individual who was involved.

\section{Improving Radio Communications}

Several recent incidents involving fire fighter fatalities where inadequate fireground communications were identified as contributing factors to the injuries and deaths prompted the U.S. Fire Administration (USFA) to study the potential causes of communication breakdown and to provide recommendations that would help departments improve operational communications.

\section{Disclaimer}

Mention of any company or product does not constitute endorsement by the National Institute for Occupational Safety and Health (NIOSH). In addition, citations to websites external to NIOSH do not constitute NIOSH endorsement of the sponsoring organizations or their programs or products. Furthermore, NIOSH is not responsible for the content of these websites. All web addresses referenced in this document were accessible as of the publication date. 
Volunteer Fire Fighter Dies After Running Out of Air and Becoming Disoriented in Retail Store in Strip Mall Fire-North Carolina

Appendix One

Self-Contained Breathing Apparatus Evaluation Report

Evaluation of Two Self-Contained Breathing Apparatuses for Potential Contribution to a Fatal Event in the Fire Service. 


\section{Volunteer Fire Fighter Dies After Running Out of Air and Becoming Disoriented in Retail Store in Strip Mall Fire-North Carolina}

As part of the National Institute for Occupational Safety and Health (NIOSH) Fire Fighter Fatality Investigation and Prevention Program (FFFIPP), investigation F2016-07 NC, the National Personal Protective Technology Laboratory (NPPTL) agreed to examine and evaluate two SCBA units identified as Scott ${ }^{\circledR}$ Safety model Air-Pak ${ }^{\circledR}$ 4.5, 4500 psi, 30 minute, self-contained breathing apparatus (SCBA). This SCBA status investigation was assigned NIOSH Task Number 20922.

The SCBA units were hand delivered to the NIOSH facility in Morgantown, West Virginia on June 28, 2016. The units were taken to the lower floor of the lab, room 1513, for secured storage. The SCBA units were then removed from storage for inspection on August 12, 2016 and placed back into secured storage until the testing on August 15, 2016.

The purpose of Respirator Status Investigations is to determine the conformance of each respirator to the NIOSH approval requirements found in Title 42, Code of Federal Regulations, Part 84. A number of performance tests are selected from the complete list of Part 84 requirements and each respirator is tested in its "as received" condition to determine its conformance to those performance requirements. Each respirator is also inspected to determine its conformance to the quality assurance documentation on file at NIOSH.

The two SCBA units were submitted to NIOSH/DSR by the fire department for evaluation. The SCBA units were delivered to NIOSH on June 28, 2016 and extensively inspected on August 12, 2016. The units were identified as Scott® Safety model Air-Pak ${ }^{\circledR}$ 4.5, 4500 psi, 30-minute, SCBA (NIOSH approval numbers, TC-13F-76CBRN). Corresponding facepieces were provided with the units. The units did not show any signs of heat damage, but exhibited signs of normal wear and tear for the unit. Only one unit arrived with a corresponding cylinder, identified as "Unit 1" for the remainder of this report. The cylinder gauge showed that the tank was empty. The mask mounted regulator (MMR) and sealing areas in both units were mostly clean. The locking assemblies did function, and the inside flanges had minimal to no scratching. The NFPA approval label was present and readable on both units. The personal alert safety systems (PASS) functioned and overall condition was good.

Both SCBA units passed the applicable performance tests conducted by NIOSH, meeting or exceeding the applicable certification requirements of Title 42, Code of Federal Regulations, Part 84. The full SCBA evaluation report is available upon request from the NIOSH National Personal Protective Technology Laboratory. The full evaluation report can also be downloaded from the NIOSH NPPTL PPE webpage at https://www.cdc.gov/niosh/npptl/ppe-

fireservice/pdfs/PinevilleFireDepartment20922.pdf 